\title{
The effects of strain and ploidy on the physiological responses of rainbow trout (Oncorhynchus mykiss) to $\mathrm{pH} 9.5$ exposure
}

\author{
by \\ William Andrew Thompson
}

B.Sc., The University of British Columbia, 2010

A THESIS SUBMITTED IN PARTIAL FULFILLMENT OF THE REQUIREMENTS FOR THE DEGREE OF MASTER OF SCIENCE

in

THE FACULTY OF GRADUATE AND POSTDOCTORAL STUDIES

(Zoology)

The University of British Columbia

(Vancouver)

April 2014

๑William Andrew Thompson 2014 


\section{Abstract}

British Columba (BC) has a well-established lake-stocking program that relies on hatchery-reared rainbow trout (Oncorhynchus mykiss) from multiple wild and domesticated strains. These strains are stocked into BC lakes as diploids and triploids and, in general, high mortality rates are common after lake stocking due to environmental conditions. Of particular concern is that some lakes in BC are approaching a pH of 9.5, and it is not known if strain and ploidy affects the physiological responses of trout to high $\mathrm{pH}$ exposure. The goal of this thesis is to understand the effects of pH exposure, in both soft and hard water, on wild and domestic strains of trout as diploids and triploids. In soft water, high pH exposure resulted in more than $40 \%$ loss of equilibrium in the wild strains of trout while the Fraser Valley domesticated strain had fewer than $10 \%$ of individuals lose equilibrium overall. There were no clear differences between ploidies in loss of equilibrium. High pH exposure caused significant increases in plasma and tissue ammonia, with no differences between strains or ploidies in ammonia accumulation. In the brain, glutamine increased in response to high $\mathrm{pH}$ exposure and glutamate decreased suggesting a protective mechanism of glutamine production in high $\mathrm{pH}$. Plasma lactate accumulated in all groups, suggesting an increase in anaerobic metabolism as a result of high $\mathrm{pH}$ exposure. There were no physiological differences between high pH exposure in hard and soft water among the strains tested. However, triploid rainbow trout suffered a greater loss of equilibrium than diploid trout, occurring in conjunction with a significant elevation of brain ammonia in triploid rainbow trout when compared to diploid trout in high $\mathrm{pH}$ water. Overall, the 
results of this thesis demonstrate an effect of strain on high $\mathrm{pH}$ tolerance in trout, but the differences in tolerance appear to not be explained by differences in ion regulation and ammonia balance. 


\section{Preface}

Chapters 2 and 3 of this thesis are co-authored by William A. Thompson, Tammy Rodela, and Jeffrey G. Richards. I conducted the research in both chapters under the supervision of Dr. Jeffrey G. Richards, with the exception of the measurements of plasma cortisol and brain composition percentages in Chapter 3, which were collected by Tammy Rodela (UBC) and an undergraduate volunteer, Amir Pourghardiri (UBC), respectively. I wrote all 4 chapters of this thesis and I received editorial feedback from Drs. Jeffrey G. Richards, Patricia Schulte, and Colin J. Brauner.

All procedures involving animals were performed using protocols approved by the Animal Care Committee, certificate A13-0024. 
Table of contents

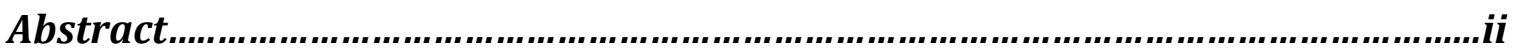

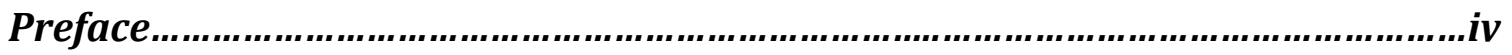

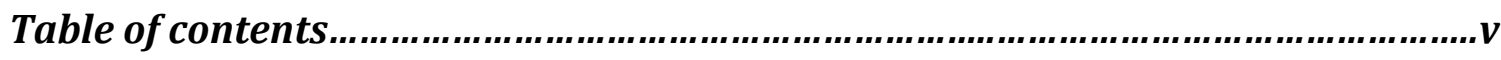

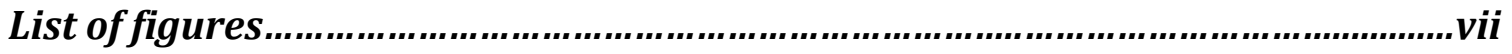

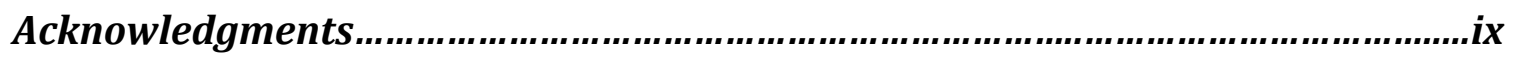

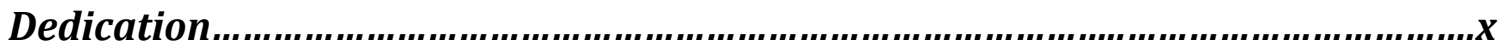

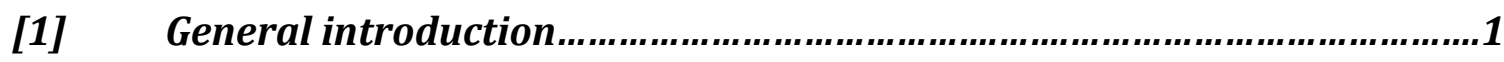

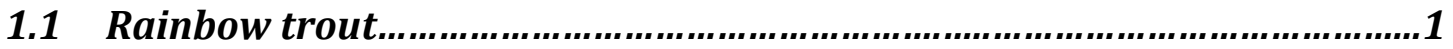

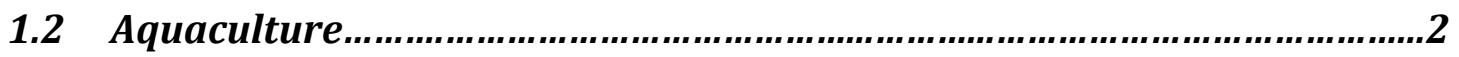

1.3 Provincial fish stocking program ....................................................

1.4 The environmental parameters of stocked lakes in British Columbia..... 7

1.5 Morphological and physiological responses to elevated ambient pH.....8

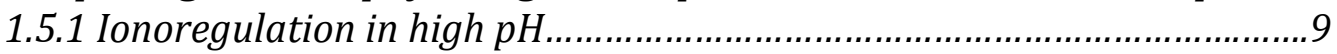

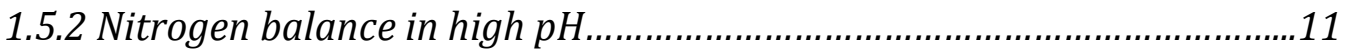

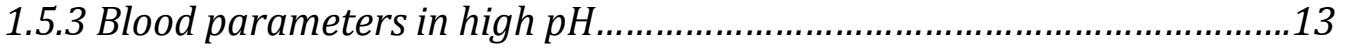

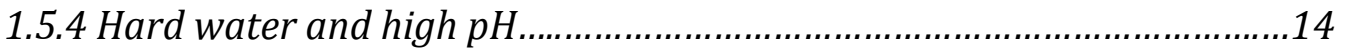

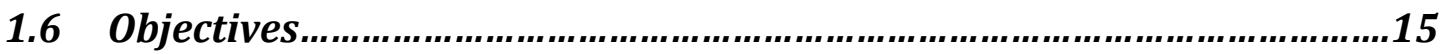

[2] The physiological effects of high pH (9.5) exposure on various strains of diploid and triploid rainbow trout (Oncorhynchus mykiss)...............16

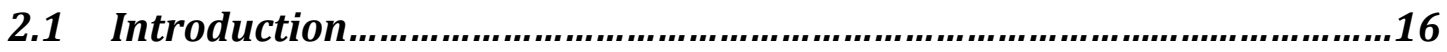

2.2 Materials and methods.......................................................................18

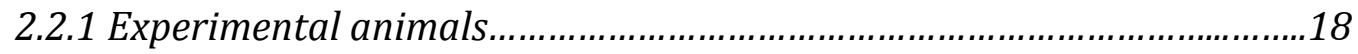

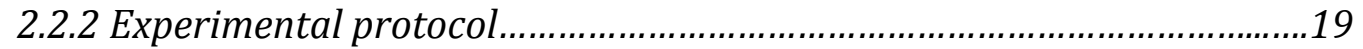

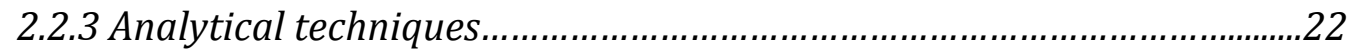

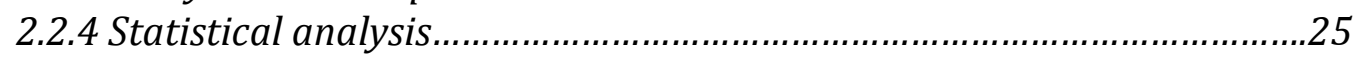

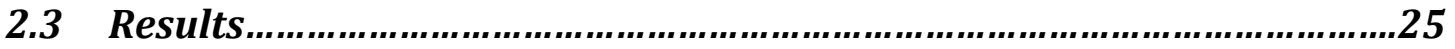

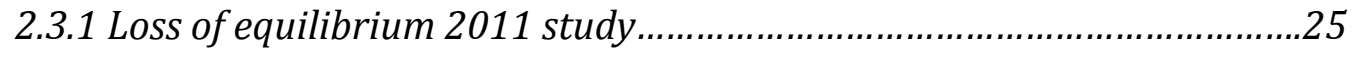




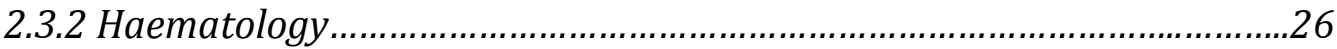

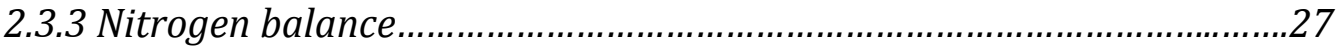

2.3.4 Loss of equilibrium 2012 study ..........................................................28

2.3.5 Brain metabolites.............................................................................28

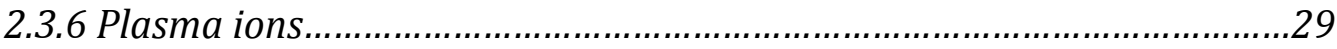

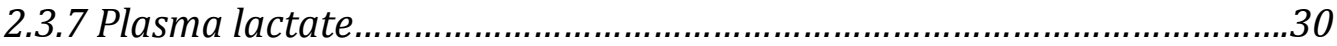

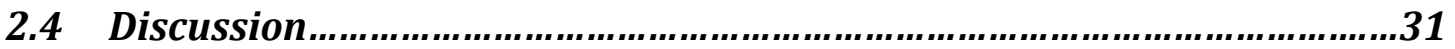

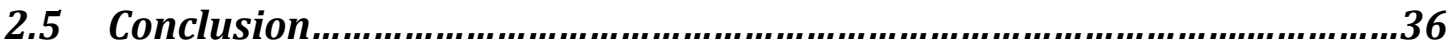

[3] The physiological response of wild and domestic strains of diploid and triploid Rainbow trout (Oncorhynchus mykiss) in hard and soft high pH (9.5) water...................................................................................43

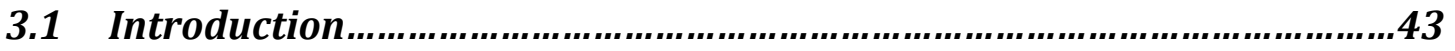

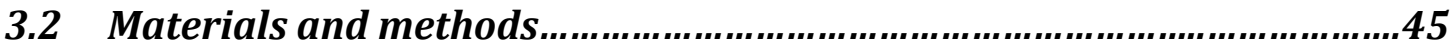

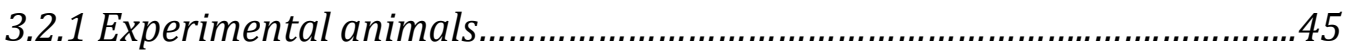

3.2.2 Experimental protocol......................................................................4

3.2.3 Analytical techniques....................................................................... 48

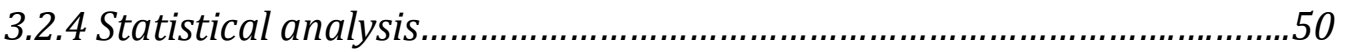

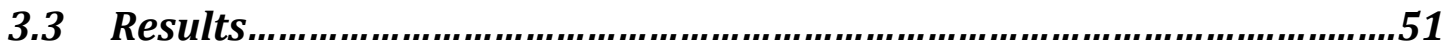

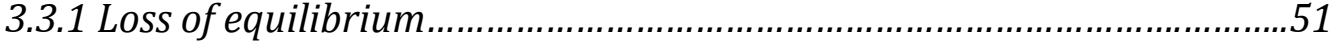

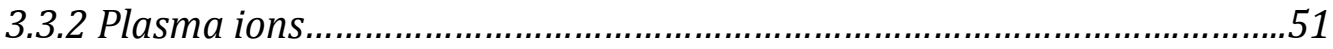

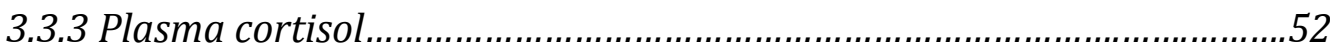

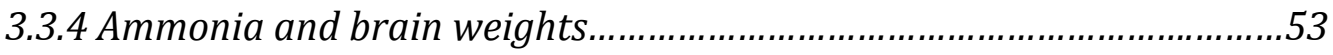

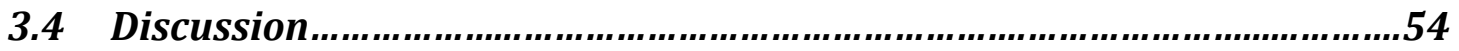

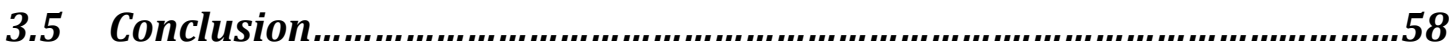

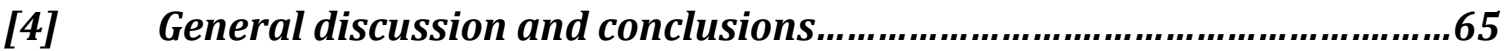

4.1 The effects of strain and ploidy on the physiological response of trout to $\mathrm{pH}$ 9.5 water

4.2 The effects of water hardness on the physiological response to high $\mathrm{pH}$ water of various strains and ploidies of rainbow trout.....................................67

4.3 Recommendations and future research.........................................................68

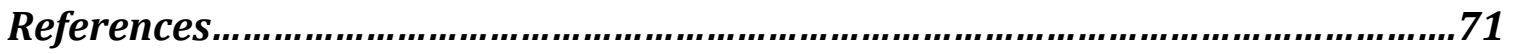




\section{List of figures}

Figure 2.1 Loss of equilibrium data from 2011 of four strains of diploid and triploid rainbow trout losing equilibrium in high $\mathrm{pH}$ (9.5) water for

48 hours.

Figure 2.2 Hemoglobin, hematocrit, and mean cell hemoglobin concentration of four strains of diploid and triploid rainbow trout in high $\mathrm{pH}$ (9.5)

water for 48 hours

Figure 2.3 Total plasma ammonia, plasma urea, and white muscle ammonia of four strains of diploid and triploid rainbow trout in high $\mathrm{pH}$ (9.5) water for 48 hours

Figure 2.4 Loss of equilibrium data from 2012 of five strains of diploid and triploid rainbow trout losing equilibrium in high $\mathrm{pH}$ (9.5) water for

72 hours.

Figure 2.5 Total brain ammonia, brain glutamate, and brain glutamine of five strains of diploid and triploid rainbow trout in high $\mathrm{pH}$ (9.5) water for 72 hours.

Figure 2.6 Plasma sodium, plasma chloride, and plasma lactate of five strains of diploid and triploid rainbow trout in high pH (9.5) water for 72 hours.

Figure 3.1 Number of diploid and triploid rainbow trout from four strains showing a loss of equilibrium after 24 hours of exposure to control, soft high pH (9.5), and hard high $\mathrm{pH}$ (9.5) water. .60

Figure 3.2 Plasma sodium and plasma chloride of diploid and triploid rainbow trout from four strains exposed to control, soft high $\mathrm{pH}$ (9.5), and hard high $\mathrm{pH}$ (9.5) water for 24 hours..... 61

Figure 3.3 Plasma cortisol of diploid and triploid rainbow trout from four strains exposed to control, soft high $\mathrm{pH}$ (9.5), and hard high $\mathrm{pH}$ (9.5) water for 24 hours.

Figure 3.4 Plasma ammonia, liver ammonia, and brain ammonia of diploid and triploid rainbow trout from four strains exposed to control, soft high pH (9.5), and hard high pH (9.5) water for 24 hours. .63 
Figure 3.5 Percent water, and percent dry mass of the brains of diploid and triploid rainbow trout from four strains exposed to control, soft high pH (9.5), and hard high pH (9.5) water for 24 hours 


\section{Acknowledgements}

I first need to thank my supervisor Dr. Jeff Richards for all he has done for me. For giving me an opportunity to prove myself in his lab, and all the time he has invested in me to be where I am today. To say I couldn't have done it without him would be the largest understatement of my life. I also must thank my committee members Dr. Trish Schulte and Dr. Colin Brauner for their guidance throughout my masters. I am indebted to Dr. Rush Dhillon for "breaking me down and building me back up correctly", and Dr. Tammy Rodela for attempting to "keep me focused on the goal". To my lab mates, Gigi Lau, Milica Mandic, Matt Regan, Dave Allen, Mark Scott, Ben Speers-Roesch, Lili Yao, Joshua Emerman, Cris Gomez, and Tara McBryan, thank you for fighting the good fight with me. Long hours in the lab were only possible because of you.

The times I had with the "Comphy" crew were incredible. Words cannot express how amazing the individuals in the department are, with special mention to Mike Sackville, Yvonne Dzal, Georgie Cox, Till Harter, Emily Gallagher, Jonathon Wong, Katelyn Tovey, Michelle Ou, and Ryan Shartau. They were always willing to talk science, celebrate the good times, and keep you going during the bad. I have to thank Betty Hsu, for her support and patience throughout the long hours and my bouts of madness. Thank you to my friends, James Chan, Kris Odulio, Anthony Chu, Terence Ng, MJ Labao, Will Chan, Conrad Nisperos, and Jamie Yuen, because I told you I would mention you at some point in this thesis. Finally, I have to thank Subway $^{\mathrm{TM}}$ and Fresh Slice ${ }^{\mathrm{TM}}$, for being my number one source of nutrition and the downfall of my physique. 
For my grandmother 


\section{[1] General introduction}

\section{General overview}

Given the rainbow trout's importance to sport fishing in British Columbia, experimentally addressing their abilities and limitations will be of great financial benefit to the province. In this thesis I assess the physiological response of diploid and triploid stains of rainbow trout to a high $\mathrm{pH}$ environment. I focus primarily on physiological changes related to ammonia balance, ionoregulation, and markers of stress.

\subsection{Rainbow trout}

Rainbow trout (Oncorhynchus mykiss) are members of the family Salmonidae and genus Oncorhynchus and are closely related to Pacific Salmon (Benhke, 2010). Rainbow trout are not to be confused with the anadromous form of Oncorhynchus mykiss, the Steelhead trout, as the rainbow trout possess a different life history in which all life stages live in a freshwater environment (McCusker et al. 2000). The body of work presented in this thesis solely focuses on the physiology and biochemistry of rainbow trout. The rainbow trout is native to the areas around the Pacific Ocean, extending from the coastline of California to Eastern Russia (McCusker et al. 2000). Geographical distributions across a variety of organisms have led to the theory that in the Pleistocene era, a path was formed from the Columbia River that allowed the radiation of the rainbow trout to previously unpopulated areas in California (Benhke, 1979). Rainbow trout have been 
introduced to a wide range of locales including Europe, Asia, Australia, Africa, South America, and are prominent on the Western and Eastern coasts of North America (MacCrimmon, 1972; Benhke, 1979). Rainbow trout prefer temperatures ranging from $13^{\circ} \mathrm{C}$ to $18^{\circ} \mathrm{C}$, and can tolerate variations of water quality, and other environmental variables (Hardy, 2002). Their range of tolerance of varied environments further advanced their propagation around the world (Keeley et al. 2005; Keeley et al. 2007). They are a major food source across the globe and as a result many countries have developed rainbow trout hatcheries to meet this demand (MacCrimmon, 1971; Benhke, 1979).

\subsection{Aquaculture}

The successful growth of fish in hatcheries allowed the development of lake stocking programs to supplement a growing recreational fishing industry. The first report of hatchery-reared rainbow trout was in the 1870's by the California Acclimatization Society (Benhke, 1979). The success of the hatchery allowed the introduction of rainbow trout to new regions throughout the United States and the world (MacCrimmon, 1972). Rainbow trout currently comprise nearly half of the 8 million fish stocked in $\mathrm{BC}$, and the system that handles stocking began to develop in the late 1880's (GSGislason and Associates Ltd, 2009). At that time, BC had 17 government run hatcheries primarily culturing sockeye salmon (Robson, 2004). These hatcheries discontinued salmon production by 1941 and shifted their focus to managing freshwater species through a provincial effort coordinated by the Ministry of Fisheries to supervise all aquaculture sites (Robson, 2004). Today, the 
culturing of freshwater fish is largely managed by a non-profit organization, the Freshwater Fishery Society of British Columbia (FFSBC), who play an integral role in maintaining a provincial fish stocking program that supports sport fishing (Robson, 2004).

\subsection{Provincial fish stocking program}

The sport fishing industry in $\mathrm{BC}$ generates over 400 million dollars in revenue from approximately 300 thousand anglers per year (Clarke, 2012). To meet this incredible demand from tourism for this activity, the FFSBC supplements high traffic lakes with fish raised in local hatcheries. Between 2004 and 2009 nearly 8 million fish were stocked annually into 837 lakes across BC, and of these stocked fish nearly 4 million were rainbow trout (GSGislason and Associates Ltd, 2009).

To accommodate the variety of environment conditions present in $\mathrm{BC}$ lakes, the FFSBC stock lakes using a variety of wild and domesticated strains. A strain is defined as a population of rainbow trout that is geographically isolated and has adapted to its local environment. It is believed that many of the adaptations are genetically based and therefore heritable (FFSBC, 2004). As a result, the FFSBC attempts to match appropriate strains to specific environments to optimize fish survival (Clarke, 2012). There are six strains that are commonly stocked in BC including four wild strains in this thesis (Blackwater, Tzenzaicut, Pennask, and Carp Lake), and one domesticated strain (Fraser Valley). Wild strains are kept in a number of broodstock lakes across BC that are maintained by the FFSBC in order to limit the number of fish removed from the original wild populations (FFSBC, 2004). 
These wild strains show differences in growth rates and display diverse preferences in diet and within lake habitat use. The Blackwater strain originates from Blackwater River, and is a fast growing, piscivore commonly stocked in lakes with large shallow shoal areas with a non-salmonid fish community (FFSBC, 2004). The Tzenzaicut strain originates from Tzenzaicut Lake, and is a piscivore as well, preferring colder, pelagic regions (FFSBC, 2004). The Pennask strain originates from Pennask Lake, and is a slow growing insectivore, preferring pelagic regions (FFSBC, 2004). The Carp Lake strain is a recent addition to the lake stocking program, and originates from Carp Lake, BC (Clarke, 2012). The Fraser Valley strain is the only domesticated strain that is currently stocked in BC. Its genetic roots originate from the McCleary strain of rainbow trout from the trout lodge hatchery in Washington, USA, and it is considered to have a fast growth rate (FFSBC, 2004).

A serious concern with stocking of hatchery-reared fish in a natural environment is the gene flow of domesticated genes into the indigenous gene pool. The combination of reversed sex rainbow trout in conjunction with a shock technique to induce triploidy creates a sterile triploid female population to be introduced for sport fishing. Triploidy is a condition that occurs naturally in some vertebrates with cells containing a third set of chromosomes as opposed to the normal two. Triploidy is typically lethal in mammals (Beatty, 1970), with few species capable of forming individuals that can reach an adult age with triploid cells (Jones et al. 1969; Dunn et al. 1970; Fechheimer et al. 1983; Lamborot and Vasquez, 1998). In rainbow trout the rate of spontaneous triplody generation is small (Thorgaard et al. 1982), yet triploid rainbow trout are typically able to survive to 
adults (Cuellar and Uyeno, 1972; Thorgaard and Gall, 1979). It is hypothesized that the natural mechanism for spontaneous triploidy in rainbow trout is the fertilization of an unreduced oocyte combined with the suppression of the second meiotic division (Cuellar and Uyeno, 1972).

Artificially, triploidy has been induced by suppressing the second meiotic division through a number of different means including pressure shock and temperature. The prevention of the second meiotic division occurs immediately after fertilization of the egg by a sperm, caused by applying a shock to prevent the extrusion of the second polar body from the fertilized egg. The effectiveness of the shock in different species is highly dependent on the time of exposure and the type of shock being used (Gillet et al. 2001; Komen and Thorgaard, 2007; Filep et al. 2009). Chemical induction by cytostatic chemicals has shown some success in Atlantic salmon for the induction of triploidy, but has also resulted in the production of tetraploid individuals (Allen and Stanley, 1979). When chemicals such as cytochalasin B have been used to induce triploidy in rainbow trout, high mortality rates have occurred (Refstie, 1981; Pawson, 2003). More successful methodology has since been found in exposure to high-heat or high-pressure environments to suppress the second meiotic division. Triploidy rates of $77-100 \%$ have been reported in Brown trout by applying different temperatures $\left(26^{\circ} \mathrm{C}-32^{\circ} \mathrm{C}\right)$ to recently fertilized eggs for a variable time course. In rainbow trout, Lincoln and Scott (1983) saw varying success with different strains receiving the same heat shock. However, heat shock may induce the purging of the sperm from the egg therefore eliminating the induction of triploidy (Thoorgard et al. 1995). The most consistent technique 
used in aquaculture to induce triploidy in rainbow trout has been the implementation of a hydrostatic pressure shock to recently fertilized eggs. The pressure can range from 7,000 to 12,000psi (Chourrout, 1984; Luo and Purdom, 1984; Lincoln, 1989; Yesaki et al. 1996) but produces near 100\% effectiveness in triploidy induction. Although this process does cause some mortality its effectiveness makes it the current mechanism of choice. At the FFSBC the treatment is strain specific and can be either a heat shock or a hydrostatic pressure shock (FFSBC, 2004).

Stocking only female fish in lakes is another important measure to prevent gene flow to natural lake populations of rainbow trout. The generation of an allfemale population starts with the production of sex reversed female rainbow trout. Reversed sex rainbow trout are normal fry females that have been introduced to a testosterone-based chemical, such as $17 \alpha$-methyltestosterone, that causes the cessation of ovary development and the production of normal testes resulting in a modified male phenotype (Kuzminksi and Dobosz, 2010). As the rainbow trout are females, they are of an XX genetic background and subsequently will only be capable of passing on an $\mathrm{X}$ chromosome to their offspring, viably producing a sterile triploid all female population.

The combination of the reversed sex rainbow trout in conjunction with the shock technique creates a sterile female population to be introduced for sport fishing. The benefits of sterility appear to be dependent on the sex of the fish made sterile. For females, sterility is believed to divert energy that would normally be used for gonadal development towards somatic growth (FFSBC, 2004). However, 
sterile triploid male rainbow trout still produce reproductive hormones, which are believed to reduce flesh quality due to the onset of secondary sexual characteristics (FFSBC, 2004).

In the wild, stocked triploid fish have been shown to have variable success in terms of survival. Studies have reported reduced triploid returns (Blanc et al. 1992; Simon et al. 1993; Dillon et al. 2000), while others report no difference between ploidies (Guo et al. 1990; Wagner et al. 2006). In BC, gillnetting assessments have reported reduced returns of triploid fish after stocking, and the exact cause of this increased mortality is unknown. There appears to be no real difference in growth, haematological, and biochemical parameters between ploidies when exposed to stress (Galbearth et al. 1994; Sadler et al. 2000), however, Scott (2012), reported reduced time to loss of equilibrium of triploid rainbow trout in hypoxia. No work has been done to explore the physiological response of triploid fish to high $\mathrm{pH}$ water.

\subsection{The environmental parameters of stocked lakes in British Columbia}

In addition to stocking $\mathrm{BC}$ 's lakes, the $\mathrm{FFSBC}$ regularly records water parameters of various lakes across the province. The society has reported increasing water $\mathrm{pH}$ in many lakes. Records have shown that lakes, such as Green Lake, have increased to a pH of almost 9.5, and are expected to continue to increase to a $\mathrm{pH}$ of 10.0 in the coming decade.

The $\mathrm{pH}$ of an aqueous environment is a measure of hydrogen concentration and is calculated by: 


$$
\mathrm{pH}=-\log _{10} \text { [Hydrogen] }
$$

and can vary due to a variety of physical and chemical factors. In the natural environment, water $\mathrm{pH}$ can be greatly influenced by photosynthesis and respiration of aquatic plants (Jones et al. 1998; Hansen, 2002), human eutrophication (Jones et al. 1998), and basic bedrock geology of the aquatic environments (Sutcliffe and Carrick, 1973; Krueger and Water, 1983). In BC, bedrock geology releases high levels of carbonates resulting in lakes with high $\mathrm{pH}$. The $\mathrm{pH}$ tolerance of hatcheryreared trout in $\mathrm{BC}$ has seen limited investigation despite the great range in lake water $\mathrm{pH}$ that these fish may be introduced to.

\subsection{Morphological and physiological responses to elevated ambient $\mathrm{pH}$}

Growth and survival are reduced upon exposure to high pH water. Studies on carp (Cyprinus carpio L.) have reported a decrease in growth rate at the larval stage in high $\mathrm{pH}$ to almost a third of that seen in more neutral waters (KorwinKossakowski, 1992). Mortality studies have reported relative tolerances of trout, with the upper limits of brook trout survival occurring at a pH of 11.0 (Daye and Garside, 1975). Jordan and Lloyd (1964) reported up to 50\% mortality in rainbow trout at a pH of 9.8 after 24h, and Daye and Garside (1975) noted histological damage of the skin at a $\mathrm{pH}$ of 10 .

High water pH impacts gill function, which ultimately leads to mortality. Daye and Garside (1976) noted superficial damage to the gill and operculum after brook trout were exposed to an ambient $\mathrm{pH}$ of 9.0, far below the levels reported for mortality (Daye and Garside, 1975; Daye and Garside, 1976). Damage to the gill was 
primarily attributed to degradation of the connective tissue between epithelial cells and the hypertrophy of mucous secreting cells and their subsequent release of excess mucous (Daye and Garside, 1976). Moreover, high pH significantly affects the tight junction proteins in the gill. Tight junctions are multifunctional apical proteins comprised of claudins, that act as junctions of cells that are present at the apical side of the gill membrane, and that are directly responsible for regulating paracellular solute movement and water flux in epithelial cells (Schneeberger and Lynch, 2004; Sandbichler et al. 2011). Low water pH causes enhanced permeability of the gill through the disruption of tight junctions (Tang and Goodenough, 2003) and the same may be true of high $\mathrm{pH}$.

\subsubsection{Ionoregulation in high $\mathrm{pH}$}

Under normal conditions, freshwater fish have to actively maintain the ionic composition of their body fluids, due to their hypo-osmotic environment (Evans et al. 1999). The exchange of electrolytes in the rainbow trout is tightly controlled by the chloride cells, or mitochondria rich cells, and to a lesser extent the pavement cells of the gill in adult fish (Avella et al. 1987; Perry and Laurent, 1989; Perry, 1997; Evans et al. 2005). Sodium levels within the body are maintained by an electrochemical gradient with a basolateral sodium-potassium ATPase (NKA), and with exchange of sodium and protons across the apical membrane (NHE) (Evans, 2011). An apical bicarbonate exchanger transports chloride, and chloride channels carry chloride ions across the basolateral membrane into the blood (Evans, 2011). 
The gill is the major ion regulatory organ in fish and it is susceptible to damage during high $\mathrm{pH}$ exposure, and various studies have reported severe ion loss of sodium $\left(\mathrm{Na}^{+}\right)$and chloride $\left(\mathrm{Cl}^{-}\right)$and large histological changes in rainbow trout exposed to high pH water (Wilkie and Wood, 1991; Yesaki and Iwama, 1992; WIlkie and Wood, 1995; Laurent et al. 2000). Sodium and chloride are the dominant ions in plasma and consequently are primary determinants of osmolality (Wood and Randall, 1973). Both of these ions play a large role in acid/base balance (McDonald and Wood, 1981; Goss and Wood, 1990; Perry et al. 1992; Goss et al. 1998), particularly in exchange for their acidic and basic equivalents, $\mathrm{H}^{+}$and $\mathrm{HCO}_{3}^{-}$(Eddy, 1976; Goss et al. 1998). Exposure to high pH water in rainbow trout results in an immediate loss of sodium to the environment, presumably due to gill damage (Wilkie et al. 1996; McGeer and Eddy, 1998; Laurent et al. 2000), despite a maintained unidirectional sodium uptake rate. High $\mathrm{pH}$ water is associated with increases to chloride cell surface area and their surface area to volume ratio, increases in the amount of surface area available for pavement cells, and a reduction of the lamellar thickness of cells at the gill (Laurent et al. 2000). Furthermore, increased secretion of mucus from epithelial cells under high $\mathrm{pH}$ conditions, as reported by Daye and Garside (1976), may provide a charged microenvironment, which can be expected to act as a trap for cations and anions such as chloride and sodium. Mucus is comprised of water, ions, and cationic glycoproteins that are secreted in high stress situations by hypertrophy of mucosal cells (Handy, 1989). 


\subsubsection{Nitrogen balance in high $\mathrm{pH}$}

Ammonia (referred to as the sum of $\mathrm{NH}_{3}$ and $\mathrm{NH}_{4}+$ ) is a by-product of amino acid catabolism and is either readily excreted across the gills, converted to another molecule for reuse, or converted to urea for release from the body (Wilkie, 2002; Randall, 2011). Rainbow trout typically excrete most of their wastes as ammonia across the gill (Wilson et al. 1994). At a normal physiological pH (7.4 to 7.8), approximately $95 \%$ of the ammonia exists as $\mathrm{NH}_{4}+$. In vertebrates, if $\mathrm{NH}_{3}$ accumulates within the body it may lead to seizures, convulsions, and even death through disruption of the central nervous system (Randall and Tsui, 2002; Monfort et al. 2002; Randall, 2011). The toxicity of ammonia is directly related to the concentration of the un-ionized form $\left(\mathrm{NH}_{3}\right)$ in the body (Smart, 1978). The proportion of $\mathrm{NH}_{3}$ compared to the ionized ammonium ion $\left(\mathrm{NH}_{4}^{+}\right)$is directly determined by the pKa ( 9.3) of ammonia, which is influenced by both temperature and pH (Emerson et al. 1975; Smart, 1978). Ammonia is typically excreted across the gill as $\mathrm{NH}_{3}$ by simple diffusion down its concentration gradient through rhesus glycoproteins (Nawata et al. 2007; Hung et al. 2008). The gill creates an acidic microenvironment by pumping $\mathrm{H}^{+}$across the apical gill creating a boundary layer or "pocket" for $\mathrm{NH}_{3}$ to interact with $\mathrm{H}^{+}$and to be converted to $\mathrm{NH}_{4}{ }^{+}$, keeping $\mathrm{NH}_{3}$ levels low and promoting further ammonia diffusion (Randall and Wright, 1989; Wilson et al. 1994). Sodium can also be exchanged for $\mathrm{H}^{+}$by the NHE to maintain this acidic "pocket" for ammonia conversion (Wright and Wood, 2009; Wright and Wood, 2012). 
Environmental $\mathrm{NH}_{3}$ increases in high $\mathrm{pH}$ water impairing ammonia excretion, and leading to an elevation in whole body ammonia (Wilkie and Wood, 1994; Wilkie et al. 1996; Wilkie, 1997). The retention of ammonia within the body increases the amount of unionized ammonia within the tissues, and it can interact with free $\mathrm{H}^{+}$to raise the intracellular $\mathrm{pH}$ of the tissues that can, in turn, affect cellular mechanisms (Randall, 2011). Studies have demonstrated that white muscle tissue increases its ammonia content 2-fold when exposed to a prolonged alkaline environment (Wilkie and Wood, 1994). Under conditions where excretion is inhibited, ammonia can be shuttled to metabolite production. Sanderson et al. (2010) reported that rainbow trout could convert ammonia to less harmful metabolites such as glutamate and glutamine in their high external ammonia exposure. The production of glutamine is expected to be a protective response to ammonia accumulation in the brain, which is sensitive to ammonia (Sanderson et al. 2010; Randall, 2011)

Ammonia can also be sequestered as another metabolite, urea, through the ornithine-urea cycle (OUC; Huggins et al. 1969; Depeche et al. 1979; Anderson, 2001). Lake Magadi tilapia (Oreochromis alcalicus grahami) live in an extremely alkaline environment $(\mathrm{pH}>10.0)$ and have adapted their metabolism to synthesize and excrete their nitrogen wastes as urea (Wood et al. 1989). While the early life stages of rainbow trout are able to synthesize urea due to the expression of OUC enzymes (Wright et al. 1995; Pilley and Wright, 2000), these same enzymes are not highly expressed in adult stages and urea is not readily used by adult rainbow trout to sequester and excrete ammonia from the body (Wright, 1995; Wilkie et al. 1996; McGeer and Eddy, 1998). 


\subsubsection{Blood parameters in high $\mathrm{pH}$}

Disturbances to haematology, changes in the hormone cortisol, and the production of lactate often indicate organismal stress. A change in the osmolarity of the plasma affects hematocrit, and this can adversely affect the viscosity of the blood (Leray et al. 1981). Hematocrit can be highly variable in blood due to stress (Wells and Weber, 1991) and measurements of hematocrit have been used as a proxy for stress in humans (Ring et al. 2008), and may potentially act as a measure of the stress response to high $\mathrm{pH}$.

Upon exposure to a stressful event, fish respond with rapid increases in the production of lactate and the stress hormone cortisol. Cortisol promotes energy metabolism in organisms (DiBattista et al. 2005) prompting the release of ammonia as a by-product of protein catabolism (Leach and Taylor, 1982; Mortimore and Poso, 1987; Van Der Booon et al. 1991). Cortisol significantly upregulates the amount of chloride cells at the gill (Laurent and Perry, 1990; Laurent et al. 1994) and can produce rapid changes in in the activity of $\mathrm{Na}^{+} / \mathrm{K}^{+}$ATPase expression (Shrimpton et al. 1994; Shrimpton and McCormick, 1999; Seidelin et al. 1999). The presence of high cortisol levels in the plasma is thought of as an indicator of stress (Weil et al. 2001; Jentoft et al. 2005); lower cortisol levels in the plasma may be representative of an organism that is more tolerant of high $\mathrm{pH}$. Lactate is produced during anaerobic metabolism (Huckabee 1958; Skinner and McLellan, 1980; Milligan and Girard, 1993; Juel, 1997), increasing in response to stress (Turner et al. 1983). In 
high $\mathrm{pH}$ experiments, lactate significantly increases immediately after exposure and returns to control levels after a few days (Wilkie et al. 1996; Wilson et al. 1998)

\subsubsection{Hard water and high $p H$}

Lakes that are near a pH of 9.5 often have hardness levels (measured as concentration of $\mathrm{CaCO}_{3}$ ) above $500 \mathrm{mg} / \mathrm{L}$, which are considerably higher than their rearing conditions at the hatchery (Intermediate hardness of 70-180mg/L). Dissolved calcium in the environment assists in maintenance of the gill, presumably by tightening leaky junctions through direct binding to the gill (Hunn, 1985; Perry and Wood, 1985). The "shoring" up of leaky channels is confirmed in other studies where the efflux of ions is often reduced upon the addition of calcium to the ambient environment (Eddy, 1975; Hunn, 1985), which also increased activity of the $\mathrm{H}^{+}$ ATPase at the gill (Lin and Randall, 1995). If increased hardness assists in reducing the normal efflux of ions across the gill, then the natural environment may play a role in maintaining ionic levels in a high $\mathrm{pH}$ environment. However, the reduced flux across the gill may prevent the formation of the acidic boundary layer, which could abolish ammonia trapping and the re-establishment of ammonia excretion after the ammonia load. The buffer capacity of hard water may also prove to be detrimental, as exposure to water buffered with glycine resulted in rainbow trout losing a significant amount of ions (McGeer and Eddy, 1998). Whether or not calcium and hardness in general will provide an advantage to our fish remains to be seen. 


\subsection{Objectives}

The goal of this thesis was to explore the physiological responses to high $\mathrm{pH}$ exposure in four strains of diploid and triploid rainbow trout. Each of the strains used in this study had varied genetic origins and one strain may have exhibited an advantageous physiological response to high $\mathrm{pH}$ water. Given the prevalence of triploidy in stocking lakes in British Columbia, assessing the physiological change of triploid trout compared to diploid trout is essential for appropriate stocking efforts. Therefore, for my first objective, I explored: the effects of strain and ploidy on the physiological responses of trout to $\mathrm{pH} 9.5$ water

For the second objective, I was aware that high pH environments are complex, and that lake settings can affect the response of an organism with its environment. Therefore, for my second objective, I investigated: the effects of water hardness on the physiological response to high $p H$ water of various strains and ploidies of rainbow trout 


\section{[2] The physiological effects of high pH (9.5) exposure on various strains of diploid and triploid Rainbow trout (Oncorhynchus mykiss)}

\subsection{Introduction}

Increases in water $\mathrm{pH}$ are known to have profound physiological effects on fish. In rainbow trout (Oncorhynchus mykiss), exposure to $\mathrm{pH}$ above 9.5 can impair ionoregulation and result in an accumulation of ammonia in blood and tissues, which if uncorrected, can result in death. Disturbances in ionoregulation occur because exposure to high $\mathrm{pH}$ causes gill damage (Daye and Garside, 1976; Wilkie and Wood, 1994), which increases mucous production, tight junction loosening, and degradation of the secondary lamellae (Daye and Garside, 1976; Heisler, 1989; Tang and Goodenough, 2003). These changes in gill structure lead to increased gill permeability and increased ion efflux across the gill (Wilkie and Wood, 1994; Wilkie et al. 1997). In response to the high-pH induced increase in gill permeability, rainbow trout up-regulate gill chloride cell density (Wilkie and Wood, 1994; Laurent et al. 2000) in an attempt to balance ions, but these mechanisms are not entirely effective as high $\mathrm{pH}$ has been shown to directly inhibit ion influx (Wilkie et al. 1999).

Trout exposed to $\mathrm{pH} 9.5$ also accumulate endogenously produced ammonia in their blood and tissues, increasing more than 3-fold in plasma (Wilkie and Wood, 1991; Wilkie and Wood, 1994) due to a pH-dependent decrease in ammonia efflux across the gills (Wright and Wood, 1985). At physiological pH, the ammonium ion $\left(\mathrm{NH}_{4}^{+}\right)$is the predominant form of ammonia in the blood and tissues (Ip et al. 2001; Randall and Tsui, 2002); when water $\mathrm{pH}$ is above the $\mathrm{pK}_{\mathrm{a}}$ for $\mathrm{NH}_{4}+\mathrm{NH}_{3}\left(\mathrm{pK}_{\mathrm{a}}=9.3\right)$, 
$\mathrm{NH}_{4}{ }^{+}$shifts towards $\mathrm{NH}_{3}$ (Cameron and Heisler, 1983). This alters the concentration gradient that normally allows the passive diffusion of ammonia, causing an ammonia accumulation in the blood and tissues (Wilkie and Wood, 1994; Wilkie et al. 1996; Wilkie et al. 1997). Ammonia is lethal at high concentrations (Randall and Tsui, 2002; Monfort et al. 2002; Ip and Chew, 2010; Randall, 2011), causing over activation of NMDA receptors (Xu and Tao, 2004; Ip and Chew, 2010). These physiological effects combined with ion loss are thought to be the primary mechanisms associated with mortality in fish exposed to high environmental $\mathrm{pH}$ (Yesaki and Iwama, 1992; McGeer and Eddy, 1998).

Over the past several decades there has been a gradual increase in $\mathrm{pH}$ of many freshwater lakes across British Columbia (BC) such that pH is presently approaching 9.5 and is expected to exceed 10 in the coming decade. The primary cause of the increasing $\mathrm{pH}$ is unknown, but bedrock geology and low flushing rates are thought to be the primary reason (Krueger and Water, 1983; Jones et al. 1998). BC has maintained an active lake-stocking program for decades with more than 4million rainbow trout (Oncorhynchus mykiss) stocked annually into 837 lakes. BC's lake stocking program uses trout from at least 6 different strains of which roughly half are stocked as triploids, and generates more than $\$ 400$ million annually. Rising $\mathrm{pH}$ in many of these lakes, particularly popular fishing lakes such as Green Lake that has already reached $\mathrm{pH} \sim 9.3$, puts continued stocking efforts in jeopardy. In order to continue a successful lake-stocking program in British Columbia it is essential to characterize the effects of high $\mathrm{pH}$ exposure on the various strains and ploidies of 
trout used by the Freshwater Fishery Society of British Columbia (FFSBC), in hopes of identifying the most high $\mathrm{pH}$ tolerant trout strain for future stocking efforts.

The objective of this study was to compare the physiological responses of exposure to $\mathrm{pH} 9.5$ among five strains of juvenile rainbow trout, four wild and one domesticated, as diploid and triploid, all of which are currently used by the FFSBC for stocking. In this study I exposed rainbow trout to $\mathrm{pH} 9.5 \mathrm{in}$ soft water and sampled blood and tissues for up to $72 \mathrm{~h}$ and analyzed aspects of ion regulation and ammonia balance. My goal was to determine whether there is an affect of strain or ploidy on the physiological effects of $\mathrm{pH} 9.5$ exposure.

\subsection{Materials and methods}

\subsubsection{Experimental animals}

This study used four wild strains and one domesticated strain of rainbow trout. The fish were obtained from the Fraser Valley freshwater trout hatchery in Abbottsford, British Columbia. Wild strains were named after their site of origin, and included strains from Blackwater River (named Blackwater), Tzenzaicut Lake (named Tzenzaicut), Pennask Lake (named Pennask), and Carp Lake (named Carp lake). Each spring, FFSBC staff collected breeding pairs of each strain from their native environment and bred three families at the Fraser Valley trout hatchery. The progeny of each family were divided, and half were allowed to develop as diploids and the fertilized eggs of the other half underwent hydrostatic pressure shock to induce triploidy, creating full siblings that differed only by ploidy. Three families of 
the Fraser Valley domesticated strain were also bred and diploid and triploid siblings were generated using the same strategy as used in the four wild strains. Strains used each year were based on availability. Fish were reared at the Fraser Valley trout hatchery until December of each year when fish were tagged with visible implant elastomere tags to distinguish between strains, ploidies, and families. In January, the wild strains were transferred to the University of British Columbia (UBC) and were housed in a common garden flow through system separated by strain. The Fraser Valley domesticated strain grows faster than the wild strains, therefore they were bred later and tagged in March of each year, transferred to the UBC in early April, and subsequently housed in the same system. At the UBC, the fish were reared for 6 months in flow through de-chlorinated Vancouver city tap water $\left(\mathrm{pH} \sim 6.7\right.$, hardness as $\left.\left[\mathrm{CaCO}_{3}\right]<17.9 \mathrm{mg} / \mathrm{L}\right)$ and were held at $10^{\circ} \mathrm{C}-15^{\circ} \mathrm{C}$ in 2011 , and $8^{\circ} \mathrm{C}-12^{\circ} \mathrm{C}$ in 2012 . Hardness was measured with a colourmetric assay (API General hardness test kit). Fish were fed twice daily with 2\% bodyweight of Bitovita fry food. All holding and experimental conditions were conducted according to the guidelines of the Canadian Council on Animal Care.

\subsubsection{Experimental protocol}

To examine the effects of $\mathrm{pH} 9.5$ exposure on diploid and triploid trout strains, two studies were conducted, with minor differences in protocol and the number of strains used. In 2011, I exposed diploid and triploid Blackwater, Tzenzaicut, Pennask and Fraser Valley trout to pH 9.5 for $48 \mathrm{~h}$. All trout were fasted for $24 \mathrm{~h}$ in their stock tank before 12 size-matched individuals of each stain and 
ploidy were transferred to a randomly chosen compartment of a 160L exposure tank. Equal numbers of each family (4 individuals/family) were included in the compartment. Trout were allowed to recover from the transfer under flow-through conditions for $24 \mathrm{~h}$. Water was circulated from the tank to a header tank using two submersible pumps and this water circulation facilitated mixing within the exposure system. After the $24 \mathrm{~h}$ recovery period, two fish of each group were sampled for plasma, muscle, brain, and gill and this sampling served as the control. Fish were removed by netting and transferred into a bucket containing $250 \mathrm{mg} / \mathrm{L}$ benzocaine. Once the fish showed loss of equilibrium (defined as an inability to maintain dorsoventral orientation) and ceased ventilating, they were removed from the anaesthetic and sampled. Whole blood was drawn into heparinized capillary tubes after caudal severance. Capillary tubes were centrifuged at $9200 \mathrm{~g}$ to separate plasma from red blood cells. Plasma was then removed and placed into a micro-centrifuge tube, frozen in liquid nitrogen, and stored at $-80^{\circ} \mathrm{C}$. I pipetted $5 \mu \mathrm{L}$ of whole blood from the exposed caudal vein and mixed in $125 \mu \mathrm{L}$ of propidium iodide solution $(125 \mu \mathrm{L}$ Citrate acid dextrose $(2.088 \%$ trisodium citrate, $2.45 \%$ glucose, $0.693 \%$ citric acid of total volume), $0.025 \mathrm{mg}$ propidium iodide, $5 \mu \mathrm{L}$ IGEPAC detergent, and $0.00425 \mathrm{mg}$ ribonuclease A) and used it for ploidy verification (details below). An additional $10 \mu \mathrm{L}$ of whole blood was taken from the caudal vein and mixed with $2 \mathrm{~mL}$ of Drabkin's reagent (Sigma \#D5941) for the spectrophotometric determination of hemoglobin concentration. Following blood sampling, a $1 \mathrm{~cm}$ segment of caudal muscle was excised, brain and the entire gill basket were excised and all tissues were immediately frozen in liquid $\mathrm{N}_{2}$ and stored at $-80^{\circ} \mathrm{C}$. Following control 
sampling, pH was adjusted from a pH of 6.7 to 9.5 over $6 \mathrm{~h}$ with the addition of $0.2 \mathrm{M}$ $\mathrm{NaOH}$ directly to the header tank. Once pH 9.5 was achieved it was maintained using a pH electrode (Cole-Parmer) connected to an alpha-560 Eutech instruments $\mathrm{pH}$ regulator. This controlled a peristaltic pump that delivered $0.2 \mathrm{M} \mathrm{NaOH}$ when measured $\mathrm{pH}$ deviated from the set point by $0.01 \mathrm{pH}$ units. The regulator was calibrated every $12 \mathrm{~h}$ and I verified water $\mathrm{pH}$ using a Fisher Scientific hand-held $\mathrm{pH}$ meter to ensure that $\mathrm{pH}$ remained at 9.5. Dissolved oxygen and water ammonia were measured every hour by a handheld-oxygen probe (Oakton Acorn Series D06) and colourmetric assay (API Ammonia test kit), to ensure oxygen levels remained above $90 \%$ air saturation and ammonia levels remained below $0.25 \mathrm{mg} / \mathrm{L}$. Water changes were performed immediately after sampling, with $\mathrm{pH} 9.5$ water at $6,12,24$, and 36h. Two more fish from each compartment were sampled at 6, 12, 24, and $48 \mathrm{~h}$ using the same protocol as outlined above. Fish were assessed for loss of equilibrium (LOE) throughout the study. LOE was established when the fish lost the ability to maintain normal dorso-ventral orientation and did not correct orientation when gently prodded with a fish net. If upon prodding, the fish could not reestablish equilibrium, it was removed and the time was recorded. No fish that lost equilibrium were sampled for tissue analysis. This experiment was replicated four times, using diploid Blackwater of $15.49 \pm 1.1 \mathrm{~g}($ mean $\pm \mathrm{SEM} ; \mathrm{n}=29)$, triploid Blackwater of $15.62 \pm 1.28 \mathrm{~g}(\mathrm{n}=25)$, diploid Tzenzaicut of $24.48 \pm 1.72 \mathrm{~g}(\mathrm{n}=26)$, triploid Tzenzaicut of $19.25 \pm 1.09 \mathrm{~g}(\mathrm{n}=22)$, diploid Pennask of $16.72 \pm 2.89 \mathrm{~g}(\mathrm{n}=26)$, triploid Pennask of $10.97 \pm 1.19 \mathrm{~g}(\mathrm{n}=26)$, diploid Fraser Valley of $20.02 \pm 0.79 \mathrm{~g}$ $(n=40)$, and triploid Fraser Valley $18.05 \pm .65 \mathrm{~g}(\mathrm{n}=40)$ for a total of 96 fish per 
replicate. Two-way ANOVA and post-hoc analysis of main effects showed a significant difference between strains $(\mathrm{p}<0.0001)$, but no significant difference in size between ploidies of a strain. This study was carried out in June of 2011.

I repeated the above experiment in 2012 with minor modifications. This study was repeated in order to collect more tissue samples for analysis and because a new trout strain, the Carp Lake strain, had become available. This experiment consisted of 3 replicates, with diploid Blackwater of $6.49 \pm 0.51 \mathrm{~g}(\mathrm{n}=36)$, triploid Blackwater of $5.92 \pm 0.41 \mathrm{~g}(\mathrm{n}=36)$, diploid Tzenzaicut of $4.91 \pm 0.26 \mathrm{~g}(\mathrm{n}=36)$, triploid Tzenzaicut of $4.41 \pm 0.12 \mathrm{~g}(\mathrm{n}=35)$, diploid Pennask of 3.78 $\pm 0.2 \mathrm{~g}(\mathrm{n}=35)$, triploid Pennask of 3.47 $\pm 0.19 \mathrm{~g}(\mathrm{n}=34)$, diploid Fraser Valley 5.31 $\pm 0.32 \mathrm{~g}(\mathrm{n}=36)$, triploid Fraser Valley of $4.49 \pm 0.13 \mathrm{~g}(\mathrm{n}=36)$, diploid Carp Lake of $5.37 \pm 0.37 \mathrm{~g}(\mathrm{n}=36)$, and triploid Carp lake of $3.99 \pm 0.18 \mathrm{~g}(\mathrm{n}=36)$. Two-way ANOVA and post-hoc analysis of main effects showed a significant difference between strains ( $\mathrm{p}<0.0001)$, but no significant difference in size between ploidies of a strain. A 160L tank was divided into 10 separate compartments with a total of 15 fish of each strain and ploidy in each compartment. Three fish were removed for sampling at 0 (control), 12, 24, and $72 \mathrm{~h}$ in the 2012 study using the protocol described above. Water changes were performed at $6 \mathrm{~h}, 12 \mathrm{~h}, 18 \mathrm{~h}, 24 \mathrm{~h}, 36 \mathrm{~h}, 48 \mathrm{~h}$, and $60 \mathrm{~h}$ with pH 9.5 water.

\subsubsection{Analytical techniques}

In 2011, plasma hemoglobin, hematocrit, mean cellular hemoglobin concentration, ammonia, urea, and white muscle ammonia was measured. In 2012, plasma sodium, chloride, lactate, brain ammonia, brain glutamate, and brain 
glutamine was measured. Capillary tubes were centrifuged at $9200 \mathrm{~g}$ to separate plasma and red blood cells and hematocrit was determined as the percent of total blood occupied by red blood cells. Hemoglobin measurements were divided by hematocrit values to give MCHC content. Separated plasma was removed from the capillary tubes, and placed into a micro-centrifuge tube and frozen in liquid nitrogen. Ploidy was confirmed in all fish using the protocol established by Arumuganathan and Earle (1991). Briefly, whole blood samples stored in the propidium iodide solution were analyzed for cell size using a FACSCalibur bench flow cytometer (BD Biosciences, California, USA). Triploidy was confirmed to be 94\% effective in 2011 and 96\% effective in 2012. Hemoglobin concentration was obtained spectrophotometrically by the methods described by Blaxhall and Daisley (1973).

Plasma was used for the analysis of total ammonia, urea, chloride, sodium, and lactate. Metabolite plasma samples were diluted in $8 \%$ perchloric acid and the homogenate was centrifuged at $18000 \mathrm{~g}$ for 10 minutes. The supernatant from the centrifuged sample was removed and neutralized in $2 \mathrm{M} \mathrm{KHCO}_{3}$, and centrifuged again at $18000 \mathrm{~g}$ for 10 minutes. The supernatant from the neutralized plasma sample was removed for analysis. Ammonia values were obtained with a commercial kit (SIGMA Cat\#A0100), using glutamate dehydrogenase and the extinction coefficient of NADH at $340 \mathrm{~nm}$ of $6,220 \mathrm{~L} / \mathrm{mol} \cdot \mathrm{cm}$. Plasma urea values were obtained by using the protocol of Rahmatullah and Boyde (1980). For sodium and chloride measurements, frozen plasma was thawed and $5 \mu \mathrm{L}$ of plasma was diluted 200 -fold in $\mathrm{dH}_{2} \mathrm{O}$. The diluted plasma sample was aliquoted into two 
separate tubes: (1) the aliquot was diluted an additional 6-fold and run through a flame photometer (Varian AA240FS) (2) the aliquot of the 200-fold diluted plasma sample was mixed with $13 \mathrm{mM}$ mercuric thiocyanate and $0.5 \mathrm{M}$ ferric nitrate and was immediately read at $480 \mathrm{~nm}$ by spectrophotometer for the determination of plasma chloride. Plasma lactate was measured using the methods outlined in Bergmeyer (1983).

White muscle was used for the analysis of total ammonia, and brain tissue was used to obtain total ammonia, glutamine, and glutamate values. Brain and white muscle ammonia were measured using the same protocol used for determination of plasma ammonia. For the determination of white muscle ammonia, briefly, white muscle tissue was isolated and ground under liquid nitrogen, pre-weighed, sonicated with $8 \%$ perchloric acid using a micro ultrasonic cell disrupter (Kontes), and neutralized with $2 \mathrm{~m} \mathrm{KHCO}_{3}$. The neutralized sample was centrifuged at $18000 \mathrm{~g}$ for $10 \mathrm{~min}$, and the supernatant was removed. Brain samples were weighed, sonicated with the same protocol as white muscle tissue, and neutralized. 5M TRIS was used to neutralize brain samples instead of $\mathrm{KHCO}_{3}$ to help buffer the neutralization reaction. Brain glutamate and glutamine concentrations were determined using a modifying version of the protocol described in Lund (1970). Neutralized homogenates were aliquoted into two separate tubes. One aliquot was subjected to an additional hydrolysis reaction, being mixed with $0.5 \mathrm{M}$ acetate buffer and $2 \mathrm{mM}$ glutaminase solution and incubated at $38^{\circ} \mathrm{C}$ for $1 \mathrm{~h}$ to convert all glutamine in the homogenate to glutamate. Both aliquots were then mixed with 0.5M Tris/Hydrazine buffer, $30 \mathrm{mM} \mathrm{NAD}^{+}$solution, $100 \mathrm{mM}$ ADP solution, and 
glutamate dehydrogenase $(1200 \mathrm{kU} / \mathrm{L})$ and incubated at room temperature for 40 minutes prior to being read on the spectrophotometer at $340 \mathrm{~nm}$. Both samples were read against a standard curve for glutamate, and taking the total glutamate from the hydrolysis reaction and subtracting the glutamate from the aliquot that did not undergo a hydrolysis reaction, I calculated glutamine. I assumed that glutamine converts to glutamate stoichiometrically.

\subsubsection{Statistical analysis}

All data are reported as mean values \pm SEM. Family was collapsed in the statistical analysis to focus on the effects of time/treatment, strain, and ploidy. Three-way analysis of variance (ANOVA) was performed on all data sets with time, strain, and ploidy as fixed variables. When interaction terms were significant, a two-way ANOVA was performed followed by a Tukey post-hoc analysis, with data sets collapsed by strain or ploidy where appropriate. LOE data was analyzed using a Kruskal-Wallis chi-squared test. All data was analyzed using R version 2.15.1.

\subsection{Results}

\subsubsection{Loss of Equilibrium 2011 study}

In 2011, a Krusakal-Wallis chi-squared test revealed a significant effect of strain on LOE $(\mathrm{p}<0.0001)$. Trout began losing equilibrium as $\mathrm{pH}$ reached 9.5 at $6 \mathrm{~h}$, with the Pennask triploid trout showing the greatest loss of equilibrium (Figure 2.1). By $12 \mathrm{~h}$ exposure to $\mathrm{pH} 9.5$, all diploid and triploid wild strains had a greater 
loss of equilibrium than the Fraser Valley domestic strain, which had no individuals suffering a LOE. By $24 \mathrm{~h}, \mathrm{pH} 9.5$ exposure caused more triploids to lose equilibrium than the diploids within the same strain. The Fraser Valley domestic strain only began to show loss of equilibrium at $24 \mathrm{~h}$, with triploid Fraser Valley domestic trout showing a greater loss of equilibrium compared with their diploid counterparts. Even at $48 \mathrm{~h}$ exposure to $\mathrm{pH} 9.5$, greater than $70 \%$ of the Fraser Valley domestic trout remained, whereas no wild strains were available to sample.

\subsubsection{Haematology}

Three-way ANOVA revealed a significant effect of time $(\mathrm{p}=0.033)$ and strain ( $p=0.0002$ ) on blood hemoglobin concentration with no significant effect of ploidy $(p=0.302)$ and no significant interaction between time and strain $(p=0.459)$, time and ploidy ( $\mathrm{p}=0.372)$, strain and ploidy $(\mathrm{p}=0.537)$, and time, strain, and ploidy $(\mathrm{p}=0.627)$ (Figure 2.2A). Three-way ANOVA determined a significant effect of time $(\mathrm{p}<0.0001)$, strain $(\mathrm{p}<0.0001)$, and ploidy $(\mathrm{p}<0.0001)$ for hematocrit $(\%)$ following exposure to $\mathrm{pH} 9.5$ and there was no significant interaction between time and strain $(\mathrm{p}=0.075)$, time and ploidy $(\mathrm{p}=0.836)$, strain and ploidy $(\mathrm{p}=0.713)$, and time, strain, and ploidy ( $\mathrm{p}=0.673$ ) (Figure 2.2B). A post-hoc analysis showed a significant decrease in all time points compared with controls, a significant increase of hematocrit in diploid trout, and that the Blackwater strain was significantly decreased from the Tzenzaicut $(\mathrm{p}=0.0005)$ and Pennask $(\mathrm{p}=0.0001)$ strains. There was no significant effect of time ( $\mathrm{p}=0.0502)$, strain $(\mathrm{p}=0.144)$, or ploidy $(\mathrm{p}=0.098)$ on mean cellular hemoglobin concentration (MCHC). There were also no significant 
interaction between time and strain $(\mathrm{p}=0.253)$, time and ploidy $(\mathrm{p}=0.503)$, strain and ploidy ( $\mathrm{p}=0.222)$, and time, strain, and ploidy $(\mathrm{p}=0.88$ ) for MCHC (Figure 2.2C).

\subsubsection{Nitrogen balance}

There was a significant effect of time $(\mathrm{p}<0.0001)$, but no effect of strain $(\mathrm{p}=0.891)$ or ploidy $(\mathrm{p}=0.477)$ on plasma ammonia (Figure $2.3 \mathrm{~A})$. There were no significant interactions between time and strain $(\mathrm{p}=0.829)$, time and ploidy $(\mathrm{p}=0.984)$, strain and ploidy $(\mathrm{p}=0.906)$, and time, strain, and ploidy $(\mathrm{p}=0.741)$. Plasma ammonia increased significantly by 6 h exposure to $\mathrm{pH} 9.5$ compared with controls, but by $12 \mathrm{~h}$ exposure to $\mathrm{pH} 9.5$, plasma ammonia decreased and was no longer significantly elevated relative to controls.

Three-way ANOVA revealed a significant effect of time ( $\mathrm{p}=0.004)$, but no effect of stain ( $\mathrm{p}=0.262)$ or ploidy $(\mathrm{p}=0.897)$ on plasma urea (Figure 2.3B). There was also no significant interaction between time and strain $(\mathrm{p}=0.812)$, time and ploidy ( $\mathrm{p}=0.503)$, strain and ploidy $(\mathrm{p}=0.909)$, and time, strain, and ploidy $(\mathrm{p}=0.903)$ between main effects for plasma urea. Post-hoc analysis of the time effect indicated that plasma urea was significantly lower at $48 \mathrm{~h}$ exposure compared with control values ( $\mathrm{p}=0.001$; Figure 2.3B).

Three-way ANOVA revealed a significant effect of time ( $\mathrm{p}<0.0001)$, and no significant effect of strain ( $\mathrm{p}=0.3443)$ and ploidy $(\mathrm{p}=0.788)$ on white muscle ammonia concentration (Figure 2.3C). There were no significant interactions between time and strain $(\mathrm{p}=0.189)$, time and ploidy $(\mathrm{p}=0.645)$, strain and ploidy $(\mathrm{p}=0.275)$, and time, strain, and ploidy $(\mathrm{p}=0.802)$ between main effects for white 
muscle ammonia. White muscle ammonia increased 3-fold over control values after 6h exposure to $\mathrm{pH} 9.5$ and remained at this elevated level for the duration of the experiment.

\subsubsection{Loss of equilibrium 2012 study}

In 2012, a Krusakal-Wallis chi-squared test revealed a significant effect of strain on LOE $(p=0.04)$. Fewer trout showed a LOE in response to $\mathrm{pH} 9.5$ exposure in 2012 (Figure 2.4) than in 2011 (Figure 2.1). Similar to the 2011 study, the Fraser Valley strain had the least number of individuals showing limited LOE throughout the exposure with only 1 individual of the Fraser Valley triploid group losing equilibrium. Among the wild strains of trout, loss of equilibrium was noted in all strains by $24 \mathrm{~h}$ and at $72 \mathrm{~h}$ the greatest total loss of equilibrium occurred in the Carp Lake diploid and Pennask triploid trout, with the least in the Fraser Valley diploid strain.

\subsubsection{Brain metabolites}

There was a significant effect of time $(\mathrm{p}<0.0001)$ and strain $(\mathrm{p}=0.001)$, but no effect of ploidy $(\mathrm{p}=0.241)$ or significant interaction between time and strain $(\mathrm{p}=0.113)$, time and ploidy $(\mathrm{p}=0.806)$, strain and ploidy $(\mathrm{p}=0.762)$, and time, strain, and ploidy ( $\mathrm{p}=0.598)$ on brain ammonia. All trout exposed to $\mathrm{pH} 9.5 \mathrm{had}$ significantly higher brain ammonia than controls $(\mathrm{p}<0.00001)$ (Figure $2.5 \mathrm{~A})$. Within strains, tukey post-hoc analysis showed that the Blackwater individuals had significantly lower brain ammonia concentrations than the Fraser Valley $(\mathrm{p}=0.003)$ 
and Pennask $(\mathrm{p}=0.002)$ strains. There was a significant effect of time $(\mathrm{p}<0.0001)$ but no significant effect of ploidy, strain or interactions on brain glutamate. Fish exposed to elevated $\mathrm{pH}$ had significantly lower brain glutamate compared to the control values $(\mathrm{p}<0.0001)$ (Figure 2.5B). All strains, except for the Tzenzaicut strain, showed a significant decrease in brain glutamate at $24 \mathrm{~h}$, and concentrations remained at this level for the duration of the exposure. The analysis reveals a significant effect of time $(\mathrm{p}<0.0001)$ and strain $(\mathrm{p}<0.0001)$ on brain glutamine. A post-hoc test revealed that $\mathrm{pH}$ exposed fish had significantly higher brain glutamine at all time points compared to the control group; the $12 \mathrm{~h}$ time point increased tissue glutamine 2.5 fold at $12 \mathrm{~h}$, and continued to increase to up to 3 -fold higher than control values at 24h (Figure 2.5C). Among strains, there was a significant difference between the Pennask, and Blackwater ( $\mathrm{p}=0.007)$, and Carp Lake ( $p=0.001$ ) strains, with the Pennask strain having significantly higher brain glutamine.

\subsubsection{Plasma ions}

There was a significant effect of time $(\mathrm{p}=0.003)$ and strain $(\mathrm{p}=0.008)$, but no significant effect of ploidy $(\mathrm{p}=0.459)$ or interaction between time and ploidy ( $\mathrm{p}=0.331)$, strain and ploidy $(\mathrm{p}=0.409)$ for plasma sodium. There was a significant interaction between strain and time in this experiment $(\mathrm{p}=0.007)$, with a post-hoc analysis revealing that plasma sodium was significantly higher following high $\mathrm{pH}$ exposure at the $12 \mathrm{~h}(\mathrm{p}=0.007)$ and $72 \mathrm{~h}(\mathrm{p}=0.011)$ compared with control fish (Figure 2.6A). At the strain level, Fraser valley domestics had plasma sodium levels 
that were significant lowers than Blackwater $(\mathrm{p}=0.028)$ and Tzenzaicut $(\mathrm{p}=0.011)$ strains.

There was a significant effect of time $(\mathrm{p}<0.0001)$ on plasma chloride, however, there was no significant of strain $(p=0.449)$ and ploidy $(p=0.455)$ or interaction between time and strain $(\mathrm{p}=0.829)$, time and ploidy $(\mathrm{p}=0.785)$, strain and ploidy $(\mathrm{p}=0.81)$, and time, strain, and ploidy $(\mathrm{p}=0.441)$. A post-hoc analysis revealed that the $24 \mathrm{~h}$ time point was significantly decreased from all other time points (Figure 2.6B).

\subsubsection{Plasma lactate}

There was a significant effect of time $(\mathrm{p}<0.0001)$ and strain $(\mathrm{p}<0.0001)$ on plasma lactate and no significant effect of ploidy $(\mathrm{p}=0.274)$. There was a significant interaction between strain and ploidy $(\mathrm{p}=0.02)$, and no significant interaction between time and strain $(\mathrm{p}=0.503)$, time and ploidy $(\mathrm{p}=0.372)$, and time, strain, and ploidy ( $\mathrm{p}=0.463)$ on plasma lactate. All plasma lactate values were significantly higher following high pH exposure compared to control individuals, with the 12 and 24h time points showing a 2-fold increase and 1.5-fold increase at 72h (Figure 2.6C). Pennask trout had significantly higher plasma lactate than the Carp Lake and Fraser Valley groups $(\mathrm{p}=0.001)$. The Pennask triploid group was significantly different from the diploid Blackwater group ( $\mathrm{p}=0.027)$, the Tzenzaicut diploids $(\mathrm{p}=0.004)$, the Carp Lake diploids ( $\mathrm{p}=0.026)$, the Carp Lake triploids $(\mathrm{p}=0.0001)$, the Fraser Valley diploids ( $p=0.003)$, and the Fraser Valley triploids $(p=0.0005)$ (Figure 2.6C). 


\subsection{Discussion}

The most striking outcome of the present study was that the Fraser Valley domesticated strain of rainbow trout were more tolerant of $\mathrm{pH} 9.5$ exposure than the four wild stains used in this study, and this was observed over two consecutive years of analysis (2011 Figure 2.1 and 2012 Figure 2.4). This is consistent with previous work comparing the responses of various trout strains to an environmental challenge, where Scott (2012) demonstrated that the Fraser Valley domesticated trout strains were more tolerant of low oxygen stress compared with wild strains. This suggests that, in general, domestication may improve how animals perform under stressful conditions. Indeed, it has been shown that domesticated strains of trout and salmon handle stress far better than their wild strains, and this better stress tolerance has been associated with a blunted cortisol response (Woodward and Strange 1987; Fevolden et al. 1991).

There was considerable variation in the time to loss of equilibrium at $\mathrm{pH} 9.5$ in the wild strains. In 2011, no wild strain was capable of surviving past $24 \mathrm{~h}$ of the high pH exposure, however, in 2012, all strains survived to $72 \mathrm{~h}$. The reason for the year-to-year variation in high $\mathrm{pH}$ tolerance is unknown, but may be associated with differences in size. The wild strains used in 2012 were significantly smaller than the trout used in 2011 (see section 2.3.2 of the methods section), however unpublished FFSBC results suggest that larger fish should be advantageous in high $\mathrm{pH}$. The role of size in high $\mathrm{pH}$ should be explored in future work.

Although the present study suggests a large effect of strain and year on high $\mathrm{pH}$ tolerance, all of the trout used in the present study appear to be far more 
sensitive to a high pH exposure compared with other studies (Wilkie and Wood, 1991; Wilkie et al. 1996; Wilson et al. 1998). Wilkie and Wood (1991) reported that free-swimming rainbow trout survived up to 5 weeks of exposure to $\mathrm{pH} 9.5$ water. There are several possible explanations for lower survival in this study compared with previously published studies. For example, the increased sensitivity in my fish may be due to the greater magnitude of change in $\mathrm{pH}$ from 6.7 to 9.5 , whereas most other studies only change pH from a control value of 8.0 to 9.5 (Wilkie and Wood, 1991; Wilkie et al. 1996; Laurent et al. 2000). Murray and Ziebell (1984) increased $\mathrm{pH}$ to 9.5 from 7.2 over $6 \mathrm{~h}$ and reported 50\% mortality, but improved survival by gradually increasing $\mathrm{pH}$ to 9.8 over 5 days demonstrating the benefit of a gradual $\mathrm{pH}$ increase. However, experiments by Wilson et al. (1998) and Yesaki and Iwama (1992), were conducted in similar conditions to this study, and only the latter reported losses in their soft water high $\mathrm{pH}$ (10.1) condition. The underlying cause of sensitivity may be again based in size of the fish, as both previous studies used adult rainbow trout (approximately 200 and 400g respectively) compared to the juvenile fish used in this study. Other studies have shown an effect of size on metabolite storage in rainbow trout (Ferguson et al. 1993). Larger fish may able to regulate a physiological disturbance better, as has been shown in larger brook trout that maintain lower blood osmolarity after transfer to seawater, than smaller trout (McCormick and Naiman, 1984). Water hardness varies between experiments as well, with many studies conducted in water of intermediate to high levels of hardness ([CaCO 3$]>140 \mathrm{mg} / \mathrm{L})$ (Wilkie and Wood, 1991; Wilkie et al. 1996), in comparison to the soft water used at the $\mathrm{UBC}\left(\left[\mathrm{CaCO}_{3}\right]<17.9 \mathrm{mg} / \mathrm{L}\right)$. 
Despite the significant effects of strain on LOE at pH 9.5, there were no apparent differences in the physiological responses of the different strains to high $\mathrm{pH}$ exposure. This may, in part, be due to the fact that I sampled surviving fish for physiological analysis, which may preclude me from defining the physiological basis for differences in loss of equilibrium between strains. In addition, it is possible that other physiological or biochemical factors, besides the ones measured here, may differ between the strains and account for the differences in high $\mathrm{pH}$ tolerance.

High pH exposure is well known to affect ammonia excretion and ionregulation in trout (Wilkie and Wood, 1994; Randall and Tsui, 2002). In particular, it has been shown previously that ammonia excretion is greatly reduced upon exposure to a high pH environment (Wilkie and Wood, 1994; Wilkie and Wood, 1995; McGeer and Eddy, 1998; Wilson et al. 1998) due to the difficulty of maintaining the blood to water ammonia excretion gradient facilitated by the acidification of the gill boundary layer (Weihrauch et al. 2009; Wright and Wood, 2009). Ammonia accumulation in tissues, like the brain, has been proposed to cause the production of reactive oxygen species that ultimately lead to death (Norenberg, 2004). The results from the present study show a 2 -fold increase in plasma ammonia after $6 \mathrm{~h}$ exposure to $\mathrm{pH} 9.5$ (Figure 2.3A). This was accompanied by a 2fold increase in brain ammonia (Figure 2.5A). Sanderson et al. (2010) showed twofold higher brain ammonia than values presented in the rainbow trout in the present study, which suggests that ammonia could accumulate to higher levels in the brains before resulting in toxicity. As ammonia can readily be incorporated into citric-acid cycle metabolites such as $\alpha$-ketoglutarate and oxaloacetate, I expected to 
see an increase in the production of glutamine to deter the amount of ammonia present in the body (Randall, 2011). This is supported by the 3-fold increase in brain glutamine levels and the reduced levels of brain glutamate upon the onset of high pH (Figure 2.5B and 2.5C). It also could be expected that ammonia could be accumulated in other, ammonia insensitive cellular compartments (i.e. muscle) in order to keep plasma levels low and minimize accumulation in the brain or other more ammonia sensitive tissues. Wilkie and Wood (1995) showed that trout white muscle had a large capacity to store ammonia because it comprises up to $65 \%$ of the body mass (Stevens, 1968). The data collected in the present study on white muscle ammonia shows an accumulation of ammonia that is rapid and to a concentration that is 7.5 times greater than observed in the blood (assuming $0.8 \mathrm{ml}$ water $/ \mathrm{g}$ of tissue for muscle), demonstrating the capacity of the white muscle to store ammonia during an accumulation.

Exposure to high pH had a small, but significant effect on plasma sodium and chloride concentrations. Greater plasma ion loss following elevated $\mathrm{pH}$ exposure was expected as a consequence of the weakening of the tight junctions at the gill and general hypertrophy that occurs in fish, like the Brook trout, exposed to high pH (Gaye and Darside, 1976; Laurent et al. 2000). The present data shows a significant decrease in plasma chloride at $24 \mathrm{~h}$ (Figure 2.6B). The subsequent removal of $\mathrm{HCO}_{3}^{-}$ may account for the recovery of chloride by $72 \mathrm{~h}$ (Figure $2.6 \mathrm{~B}$ ), via the $\mathrm{Cl}^{-} / \mathrm{HCO}_{3}^{-}$ exchanger at the gills. This is speculative, as I did not measure $\mathrm{HCO}_{3}{ }^{-}$, however soft water high $\mathrm{pH}$ studies have shown increases in $\mathrm{HCO}_{3}^{-}$as a result of high $\mathrm{pH}$ exposure (Heming and Blumhagen, 1988; Yesaki and Iwama 1992, McGeer and 
Eddy, 1998) suggesting the presence of $\mathrm{HCO}_{3}{ }^{-}$reserves for exchange. I expected sodium levels to drop as reported in other studies (Wilkie and Wood, 1993; Wilkie and Wood, 1995), but rather saw limited change in sodium much like the study by Wilkie et al. (1996). The additional 0.01M sodium from the $\mathrm{NaOH}$ used to adjust the $\mathrm{pH}$ may have assisted in maintaining plasma sodium values. The limited change in plasma sodium and chloride suggest that osmoregulation was generally maintained in the trout strains during exposure to $\mathrm{pH} 9.5$, which is further supported by the relatively stable effect of pH 9.5 exposure on blood hemoglobin, hematocrit, and MCHC (Figure 2.2A; 2.2B; 2.2C). The results indicate a significant increase in lactate initially, followed by a return to control values by $72 \mathrm{~h}$. This transient increase is similar to the one reported by Wilson et al. (1998), where lactate remained significant elevated at 72h in high pH (9.5) exposed fish, but returned to control values by $96 \mathrm{~h}$. The increase in lactate reported in this study suggests that my fish use anaerobic metabolism upon exposure to high $\mathrm{pH}$, although the cause of the increase in lactate is unknown.

There is no clear and consistent effect of ploidy on any of the responses of the trout to high $\mathrm{pH}$ exposure. The lack of an effect of ploidy is consistent with other studies that have seen similar results with no real difference in growth, hematological and biochemical parameters between ploidies when exposed to stress (Galbearth et al. 1994; Sadler et al. 2000). Gillnetting returns by the FFSBC and other studies have shown reduced triploid returns in the wild (Blanc et al. 1992; Simon et al. 1993; Dillon et al. 2000), however others report no difference between ploidies (Guo et al. 1990; Wagner et al. 2006). The data does not support triploid 
sensitivity to high $\mathrm{pH}$ water, but an in-lake study would need to be run to confirm if ploidy adversely affects high $\mathrm{pH}$ tolerance.

\subsection{Conclusion}

The results of this study demonstrate that the Fraser Valley strain of trout is more tolerant of pH 9.5 compared with 4 wild strains; however, I did not discover a physiological explanation for this greater high $\mathrm{pH}$ tolerance. The Fraser Valley strain was visibly sessile throughout the exposure (personal observation), which may minimize energy expenditure and contribute to their greater high $\mathrm{pH}$ tolerance. Future studies should examine aspects of energy balance in trout exposed to high $\mathrm{pH}$ and determine if some form of metabolic rate suppression is responsible for the enhanced tolerance of the Fraser Valley trout. The natural environments of the wild strains used in this study are typically found in mountainous regions where water has a relatively high level of $\mathrm{CaCO}_{3}$. Measuring tolerance in a high $\mathrm{pH}$ environment more similar to a natural environment of the brood stocks may give a better representation of each strains actual level of tolerance in a high $\mathrm{pH}$ setting which is the focus of the next chapter. 


\section{Figures}

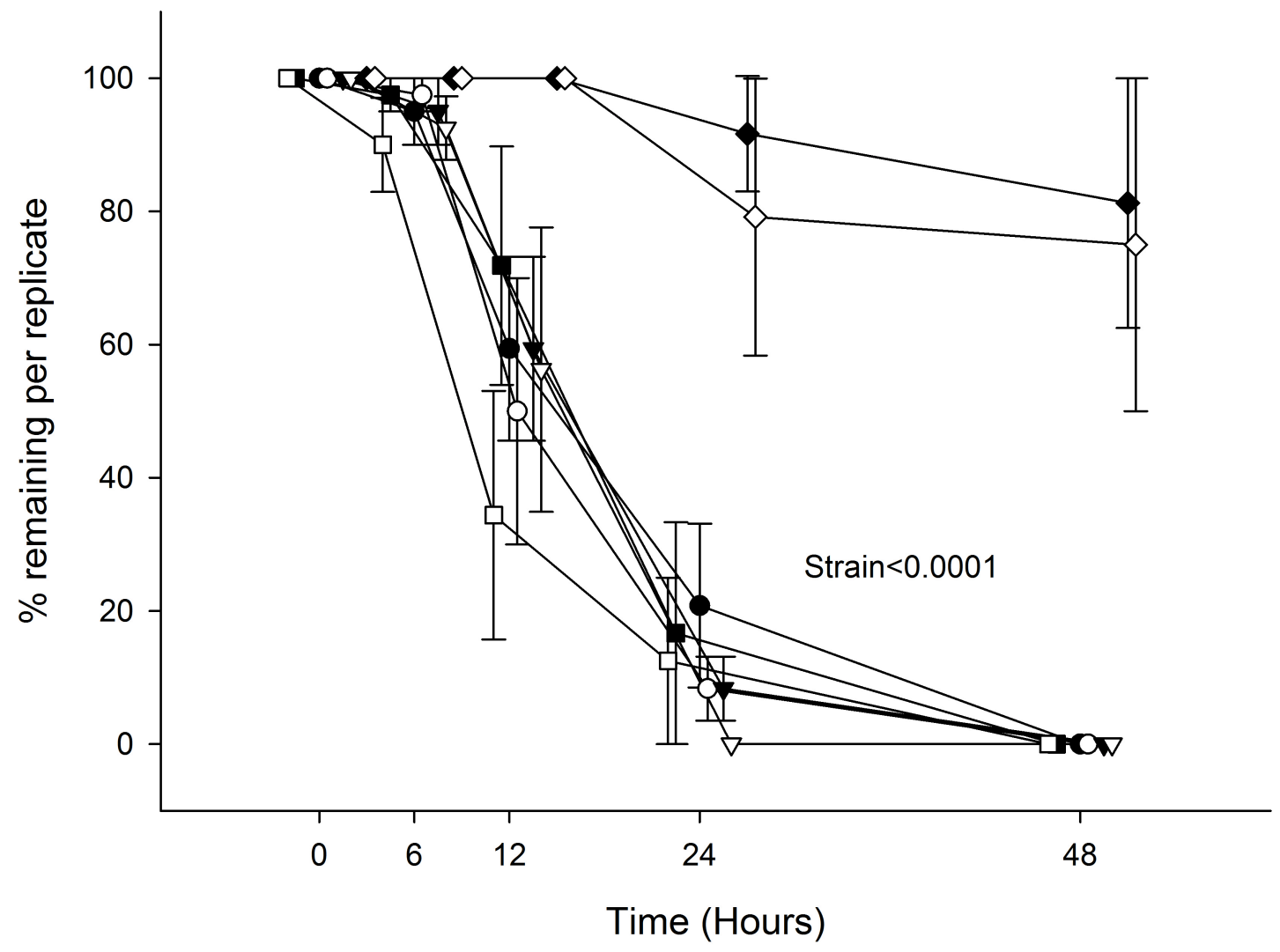

Figure 2.1. LOE data from 2011 showing the Blackwater (circles), Tzenzaicut (downward triangles), Pennask (squares), Fraser Valley (diamonds) strains and their diploid (filled symbols) and triploid (open symbols) conditions exposed to high $\mathrm{pH}$ (9.5) water for $48 \mathrm{~h}$ ( $\mathrm{n}=4$ for all data points). All groups have been staggered at their respective time points for clarity of viewing. P values from significant main effects are denoted on figure. 


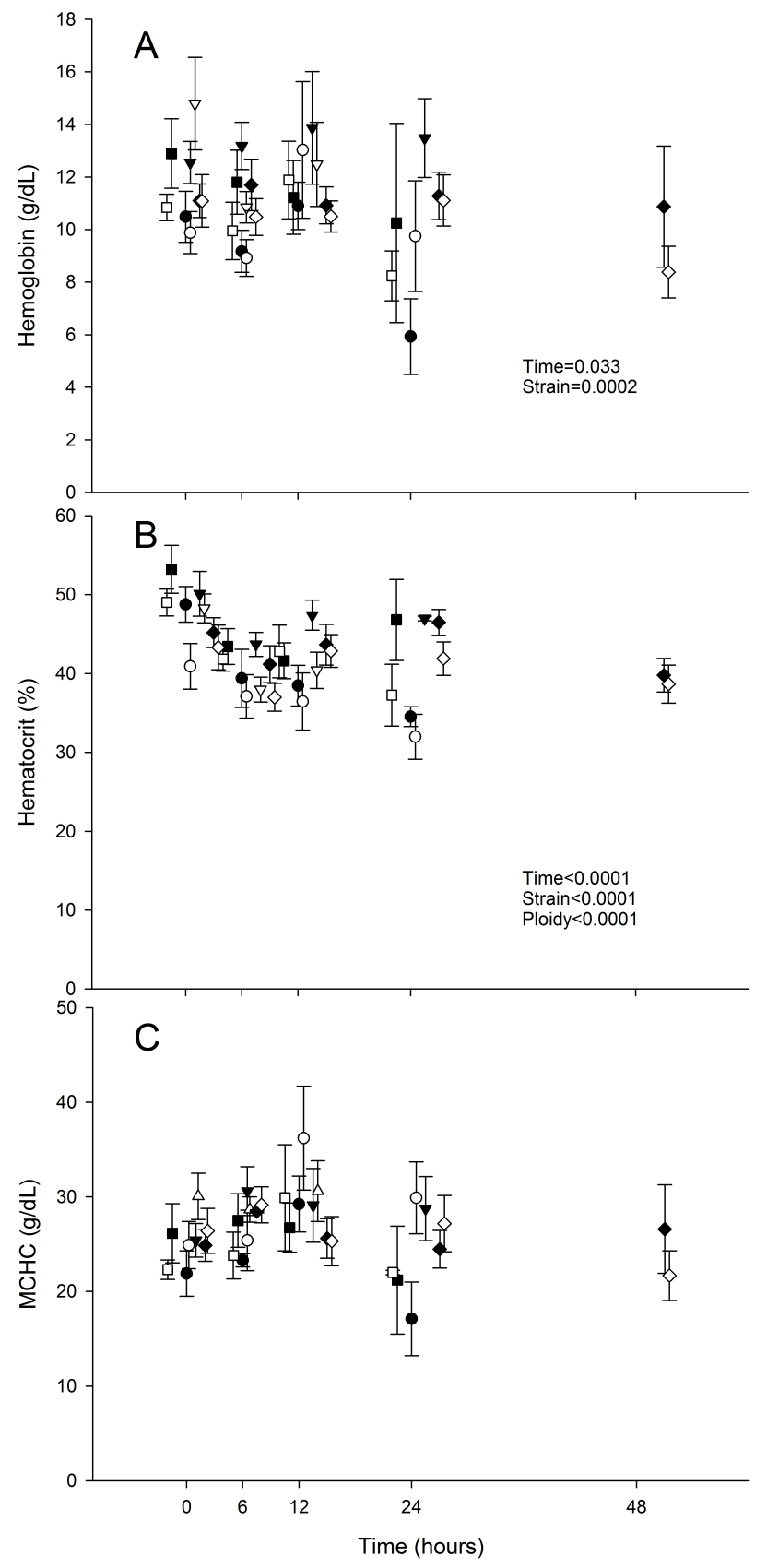

Figure 2.2. Hemoglobin concentration (A), hematocrit \% (B), and Mean Cell Hemoglobin concentration in Blackwater (circles), Tzenzaicut (downward triangles), Pennask (squares), Fraser Valley (diamonds), Carp lake (upward triangles) strains and their diploid (filled symbols) and triploid (open symbols) conditions exposed to high $\mathrm{pH}$ (9.5) water for $48 \mathrm{~h}(\mathrm{n}=2-5$ for all groups except Fraser Valley $(n=8)$ at $24 \mathrm{~h}$ mark). All groups have been staggered at their respective time points for clarity of viewing. P values from significant main effects are denoted on figure. 


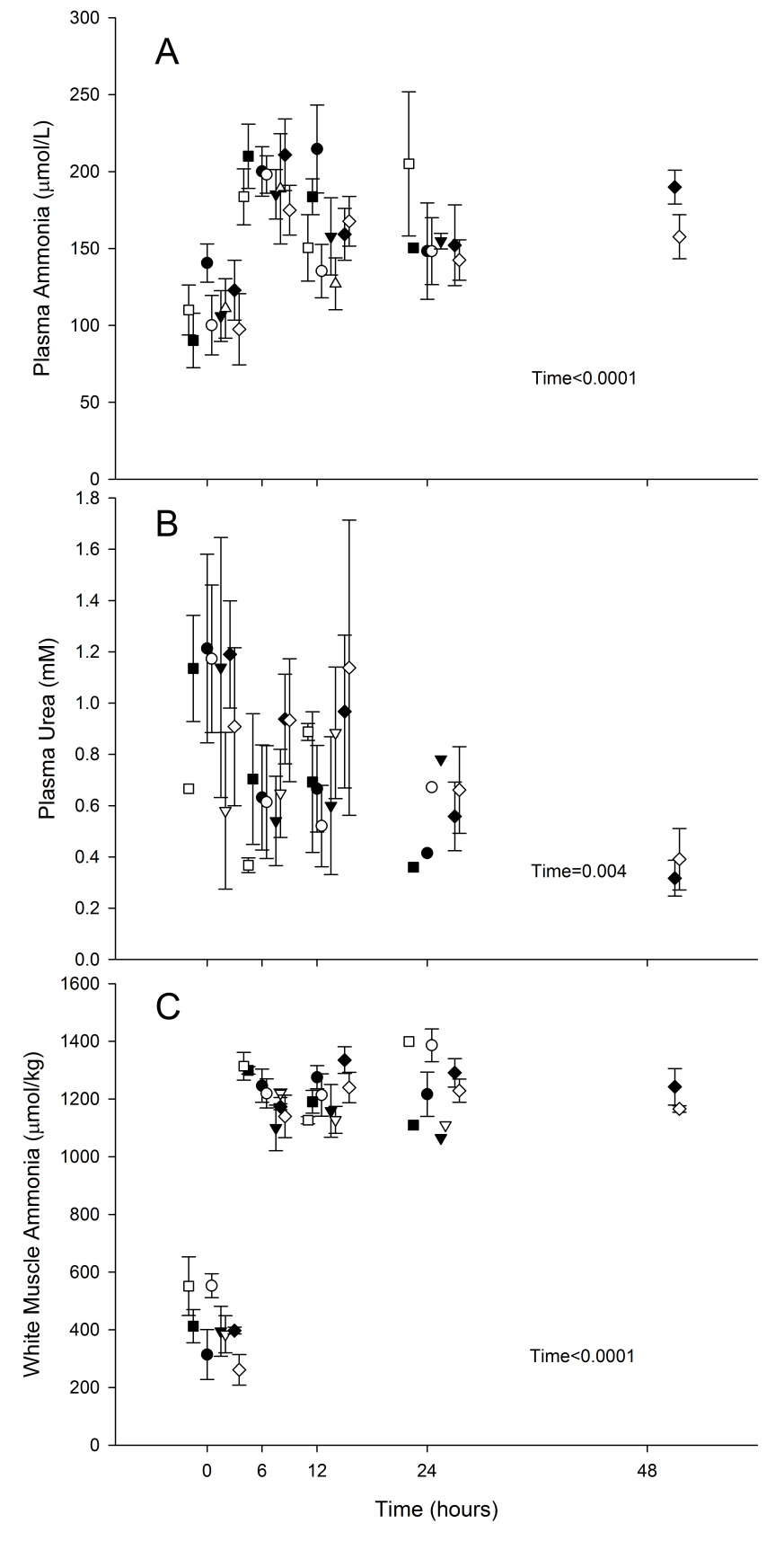

Figure 2.3. Total plasma ammonia (A), plasma urea (B), and white muscle ammonia (C) in Blackwater (circles), Tzenzaicut (downward triangles), Pennask (squares), Fraser Valley (diamonds), Carp lake (upward triangles) strains and their diploid (filled symbols) and triploid (open symbols) conditions exposed to high pH (9.5) water for $48 \mathrm{~h}(\mathrm{n}=2-5$ for all groups except Fraser Valley $(\mathrm{n}=8)$ at $24 \mathrm{~h}$ mark for A and C; $n=1-2$ for all groups except Fraser Valley $(n=8)$ at 24 h mark for B). All groups have been staggered at their respective time points for clarity of viewing. P values from significant main effects are denoted on figure. 


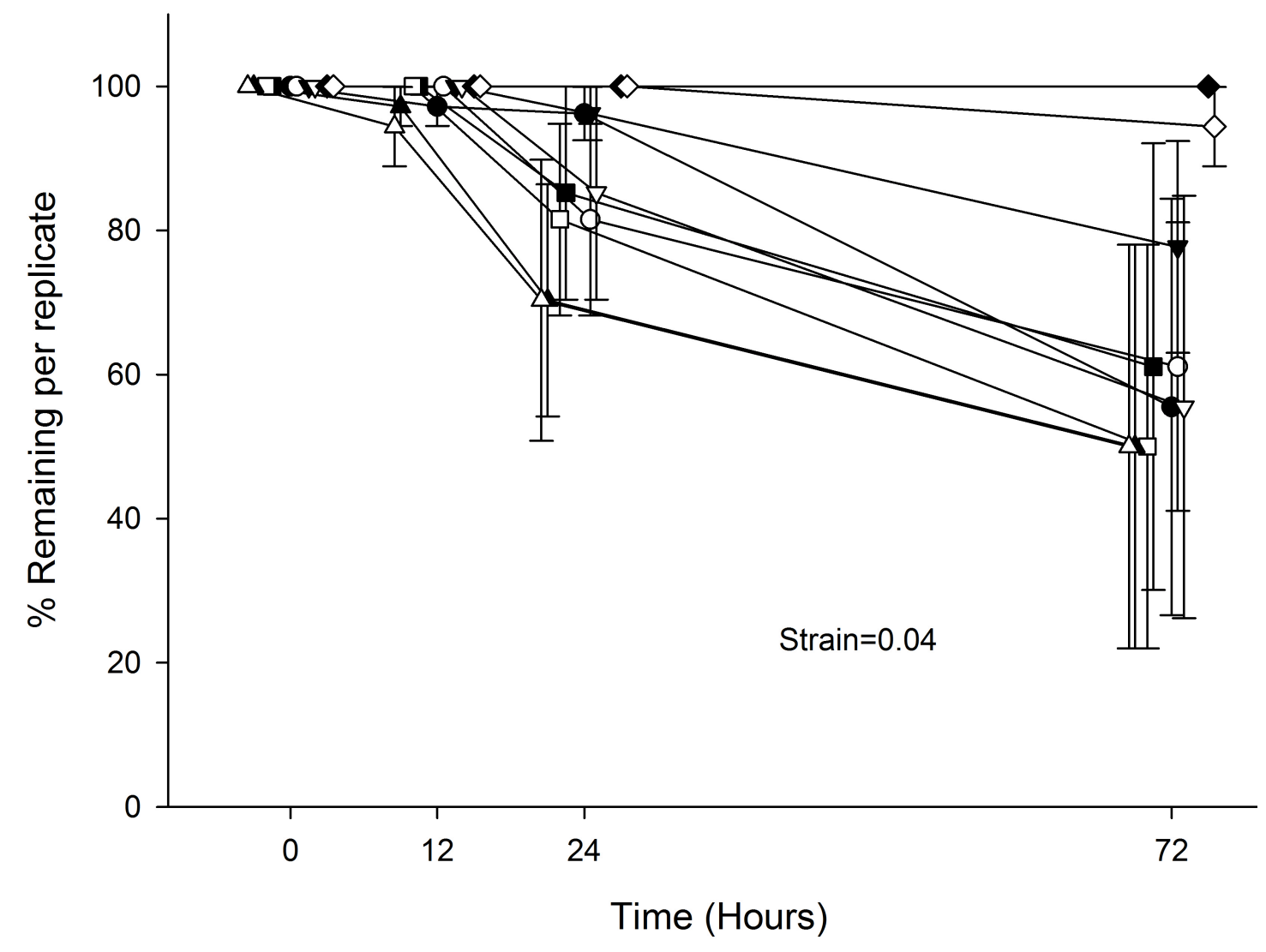

Figure 2.4. LOE data from 2012 showing the Blackwater (circles), Tzenzaicut (downward triangles), Pennask (squares), Fraser Valley (diamonds), Carp lake (upward triangles) strains and their diploid (filled symbols) and triploid (open symbols) conditions exposed to high $\mathrm{pH}$ (9.5) water ( $\mathrm{n}=3$ for all data points). All groups have been staggered at their respective time points for clarity of viewing. $P$ values from significant main effects are denoted on figure. 


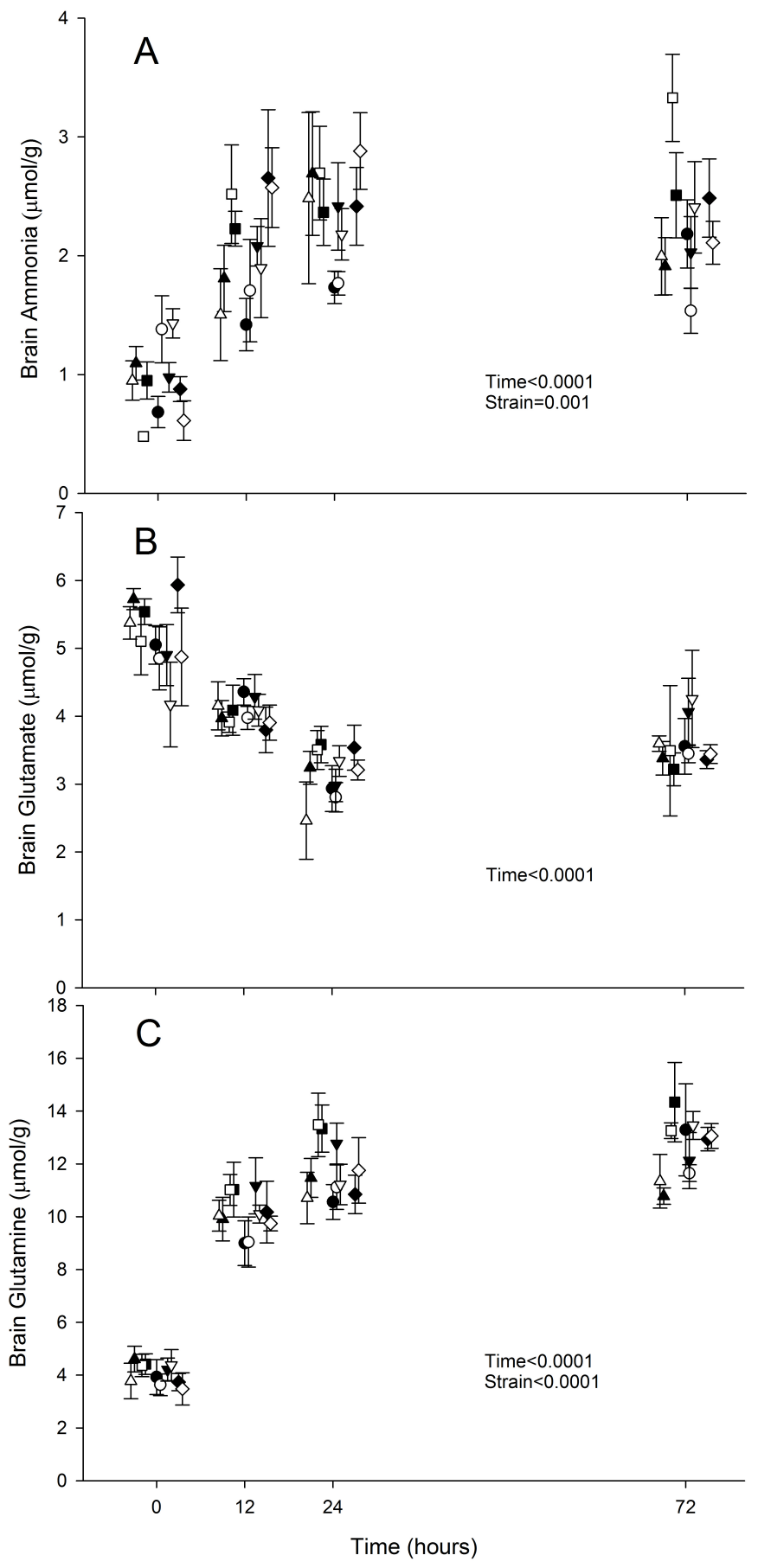

Figure 2.5. Total brain ammonia (A), brain glutamate (B), and brain glutamine (C) in Blackwater (circles), Tzenzaicut (downward triangles), Pennask (squares), Fraser Valley (diamonds), Carp lake (upward triangles) strains and their diploid (filled symbols) and triploid (open symbols) conditions exposed to high $\mathrm{pH}$ (9.5) water for $72 \mathrm{~h}(\mathrm{n}=5-8$ for all groups except at $72 \mathrm{~h} ; \mathrm{n}=3-8$ for all groups at $72 \mathrm{~h})$. All groups have been staggered at their respective time points for clarity of viewing. P values from significant main effects are denoted on figure. 


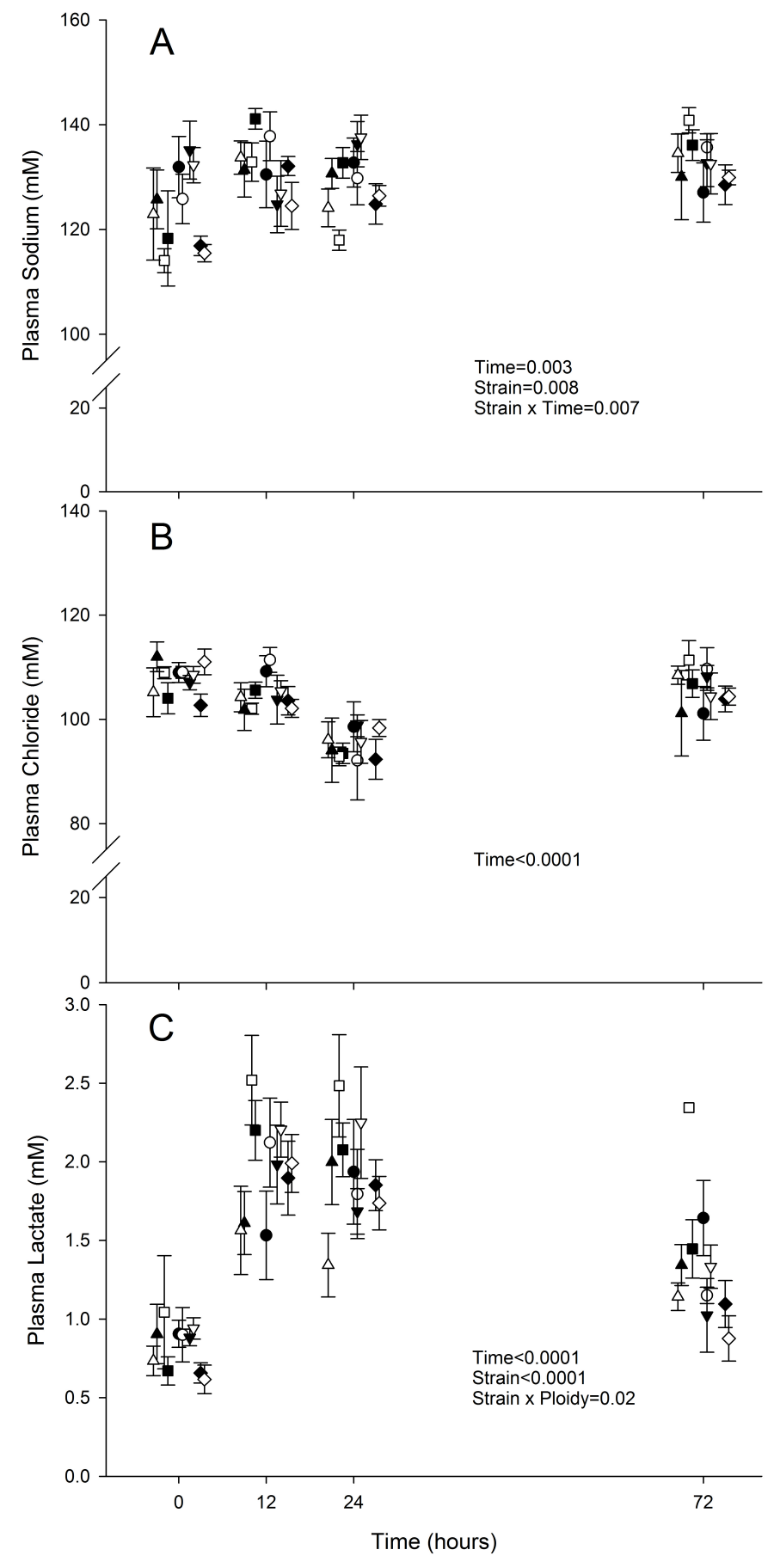

Figure 2.6. Plasma sodium (A), plasma chloride (B), and plasma lactate (C) in Blackwater (circles), Tzenzaicut (downward triangles), Pennask (squares), Fraser Valley (diamonds), Carp lake (upward triangles) strains and their diploid (filled symbols) and triploid (open symbols) conditions exposed to high $\mathrm{pH}$ (9.5) water for $72 \mathrm{~h}(\mathrm{n}=5-8$ for all groups except at $72 \mathrm{~h} ; \mathrm{n}=3-8$ for all groups at $72 \mathrm{~h})$. All groups have been staggered at their respective time points for clarity of viewing. P values from significant main effects and interactions are denoted on figure. 


\section{[3] The physiological response of wild and domestic strains of diploid and triploid rainbow trout (Oncorhynchus mykiss) in hard and soft high pH (9.5) water}

\subsection{Introduction}

British Columbia (BC) has a rich history of stocking lakes with rainbow trout (Oncorhynchus mykiss) to support recreational fishing. At least 6 different strains originating from lakes, rivers, and hatcheries are stocked across BC every year, resulting in the addition of over 4 million trout to freshwater lakes (GSGislason and Associates Ltd, 2009). To mitigate the genetic influence this addition would have on indigenous populations of trout, hatcheries commonly stock sterile triploid trout to prevent genetic mixing between stocked and native trout populations. However, numerous published reports have shown a reduced survival of triploid trout in natural settings compared with their diploid counterparts (Blanc et al. 1992; Simon et al. 1993; Dillon et al. 2000). The Freshwater Fishery Society of BC (FFSBC) is also facing the startling trend of increasing $\mathrm{pH}$ in freshwater lakes in $\mathrm{BC}$, with lakes increasing to a pH near 9.5 as a result of their bedrock geology and low flushing rates (Krueger and Water, 1983; Jones et al. 1998). The FFSBC and other agencies have reported reduced returns and survival of stocked trout in high pH lakes (Yesaki and Tsumura, 1992; Mathias et al. 1996; Wagner et al. 1997), and a pH of 9.5 has been reported to result in severe physiological responses in rainbow trout used for stocking (Chapter 2). 
Previous work demonstrated that there is an effect of strain on high $\mathrm{pH}$ tolerance in trout, with the Fraser Valley domestic strain being more tolerant of $\mathrm{pH}$ 9.5 exposures than four wild strains (Chapter 2). However, despite large differences in tolerance, there were no significant differences between domestic and wild strains in ammonia and ion balance (Chapter 2). My previous study was conducted using de-chlorinated Vancouver City tap water, which is considered to be soft $\left(\left[\mathrm{CaCO}_{3}\right]<17.9 \mathrm{mg} / \mathrm{L}\right)$ and does not reflect the water hardness seen in many of BC's lakes (Unpublished FFSBC data).

A high level of water hardness $\left(\left[\mathrm{CaCO}_{3}\right]=320 \mathrm{mg} / \mathrm{L}\right)$ enhances survival in rainbow trout exposed to high $\mathrm{pH}$ (Yesaki and Iwama, 1992). Hard water is expected to strengthen tight junctions at the gill, which results in less ion loss from the plasma to the freshwater environment (Hunn, 1985; Tang and Goodenough, 2003). Furthermore, increases in water hardness affects ammonia excretion in trout exposed to high $\mathrm{pH}$. In soft water, high $\mathrm{pH}$ exposure results in an accumulation of ammonia in plasma and tissues due to an inhibition of ammonia efflux across the gills (Wilkie and Wood 1994; Wilkie et al. 1996; Wilkie, 1997), which is partially alleviated in hard water (Yesaki and Iwama, 1992; Iwama et al. 1997; Wilson et al. 1998).

The goals of this study were to compare the short-term physiological response of diploid and triploid trout from one domestic and three wild strains to pH 9.5 exposure in both soft water $\left(\left[\mathrm{CaCO}_{3}\right]<17.9 \mathrm{mg} / \mathrm{L}\right)$ and hard-water $\left(\left[\mathrm{CaCO}_{3}\right]=320 \mathrm{mg} / \mathrm{L}\right)$. To accomplish this, I measured the changes in plasma ions, cortisol, and levels of ammonia in the plasma, liver, and brain as well as brain water 
content after $24 \mathrm{~h}$ exposure. Fish were abruptly transferred from soft water control conditions (pH 6.7) to soft water controls, soft water at $\mathrm{pH} 9.5$ and hard water at $\mathrm{pH}$ 9.5 and I recorded any loss of equilibrium (LOE) of trout in each condition.

\subsection{Materials and methods}

\subsubsection{Experimental animals}

Strains were obtained based on their availability, and in this study I used three wild strains and one domesticated strain of rainbow trout. For the wild strains, three breeding pairs were taken from their natural environment and crossed at the hatchery. Wild strains were obtained from Blackwater River (named

Blackwater), Pennask Lake (named Pennask) and Carp Lake (named Carp lake). Half of the progeny from each pair were allowed to develop as diploid fish, while the remainder was exposed to a hydrostatic pressure shock during development to induce triploidy. This created full siblings from three families that differed only by ploidy. The domestic Fraser Valley strain (named Fraser Valley) was crossed several months after the wild strains, producing diploid and triploid full siblings by the same protocol described above. Fish were reared at the Fraser Valley fish hatchery until December of 2012, when the fish were tagged with visible implant elastomere tags to distinguish strain, ploidy, and family prior to transfer from Abbotsford to the University of British Columbia (UBC) in January of 2013. Fraser Valley domestics were tagged in March of 2013, and brought to the UBC in early April of the same year. At the UBC, all trout were held in a partially re-circulated common garden 
system using de-chlorinated Vancouver city tap water $(\mathrm{pH} \sim 6.7$;

$\left.\left[\mathrm{CaCO}_{3}\right]<17.9 \mathrm{mg} / \mathrm{L}\right)$. The fish were reared until June of 2013 at the UBC and fed twice daily Monday to Friday, and once daily on weekends for a total of $2 \%$ bodyweight of Bitovita 1.2mm fry food. All holding and experimental conditions were conduced until the guidelines of the Canadian Council on Animal Care.

\subsubsection{Experimental protocol}

Fish were fasted $24 \mathrm{~h}$ before being sorted and size matched. For this experiment, diploid Blackwater trout were 9.68 $\pm 0.16 \mathrm{~g}(\mathrm{n}=24)($ Mean \pm S.E.M), the triploid Blackwater were 9.56 $\pm 0.19 \mathrm{~g}(\mathrm{n}=22)$, the diploid Pennask were 9.08 $\pm 0.16 \mathrm{~g}$ $(\mathrm{n}=24)$, the triploid Pennask were $8.21 \pm 0.16 \mathrm{~g}(\mathrm{n}=24)$, the diploid Carp lake were $10.09 \pm 0.3 \mathrm{~g}(\mathrm{n}=24)$, the triploid Carp lake were 9.58 $\pm 0.48 \mathrm{~g}(\mathrm{n}=21)$, the diploid Fraser valley were $5.34 \pm 0.3 \mathrm{~g}(\mathrm{n}=24)$, and the triploid Fraser Valley strain weighed $5.28 \pm 0.18 \mathrm{~g}(\mathrm{n}=24)$. Two-way ANOVA revealed a significant difference between strains ( $\mathrm{p}<0.0001)$, but not between ploidies or treatments within a strain for size. Four trout from each strain and ploidy were placed into 4L opaque plastic jars that had 4 square sections of the sides replaced with mesh and was covered with transparent plastic to allow observations of specimens throughout the exposure. After fish were placed into each plastic container, they were put back into the stock tank. Polyethylene foam was used for flotation of each container. The fish were allowed to acclimate to the container for $24 \mathrm{~h}$, before being placed into a mobile 150L tank for transport to the experimental chamber, where they were moved into the experimental exposure system. 
Three, blue 150L oval experimental tanks were set up at least $24 \mathrm{~h}$ before exposures, consisting of a soft water control condition $\left(\mathrm{pH}=6.7 ;\left[\mathrm{CaCO}_{3}\right]<17.9 \mathrm{mg} / \mathrm{L}\right)$, a soft water high $\mathrm{pH}\left(\mathrm{pH}=9.5 ;\left[\mathrm{CaCO}_{3}\right]<17.9 \mathrm{mg} / \mathrm{L}\right)$ condition, and a hard water high $\mathrm{pH}\left(\mathrm{pH} 9.5 ;\left[\mathrm{CaCO}_{3}\right]=320 \mathrm{mg} / \mathrm{L}\right)$ condition. The soft water treatment used dechlorinated Vancouver city tap water with the addition of $0.2 \mathrm{M} \mathrm{NaOH}$ to maintain a $\mathrm{pH}$ of 9.5. Two pumps circulated water to a header tank where $\mathrm{NaOH}$ was added and mixed via heavy aeration before being returned to the exposure tank. The control tanks followed the same protocol without the addition of $\mathrm{NaOH}$. The hard water condition consisted of $38.5 \mathrm{~g} \mathrm{CaCl}_{2} \cdot 2 \mathrm{H}_{2} \mathrm{O}, 3.2 \mathrm{~g} \mathrm{CaCO}_{3}$, and $34.6 \mathrm{~g} \mathrm{MgCl}_{2} \cdot 6 \mathrm{H}_{2} \mathrm{O}$ addition to the tank (150L) for a final hardness of $320 \mathrm{mg} / \mathrm{L}$ as $\mathrm{CaCO}_{3}$. The $\mathrm{pH}$ of 9.5 was maintained by addition of $0.2 \mathrm{M} \mathrm{NaOH}$. $\mathrm{NaOH}$ addition for the alkaline soft/hard treatments was controlled by use of a Cole-Parmer electrode connected to an alpha560 Eutech instruments $\mathrm{pH}$ regulator that electrically manipulated a peristaltic pump. Tanks were observed every hour and $\mathrm{pH}$ was maintained at 9.5. To ensure proper mixing in the hard water exposure, a total of four circulating pumps were placed in the bottom of the tank to create circular flow, and agitation was supplemented with heavy aeration. Hardness was measured with a colourmetric assay (API General hardness test kit). Each tank was covered with opaque plastic sheeting. This set up was identical for each condition.

Fish were exposed to each treatment for $24 \mathrm{~h}$. To sample the fish, a container with four fish was removed and fish were anesthetized by the addition of MS-222 (buffered with sodium bicarbonate) to a final concentration of $0.1 \mathrm{~g} / \mathrm{L}$ directly into the container. All 4 fish were removed and fork length, weight, and elastomere tag 
position were recorded. The collection of blood and tissue samples was identical to the protocol described in the previous chapter (Chapter 2). Briefly, whole blood was drawn into heparinized capillary tubes after caudal severance, and an additional $5 \mu \mathrm{L}$ of whole blood was pipetted from the exposed caudal vein to be mixed with $125 \mu \mathrm{L}$ of propidium iodide solution for determination of ploidy. I then excised a posterior $1 \mathrm{~cm}$ segment of caudal muscle, sliced open the cranial cavity to extract brain tissue, and dissected the entire gill basket out. Samples were wrapped in aluminum foil, flash frozen in liquid nitrogen, and stored at $-80^{\circ} \mathrm{C}$. Capillary tubes were centrifuged at $9200 \mathrm{~g}$ to separate plasma from red blood cells. Plasma was removed and placed into a micro-centrifuge tube, frozen in liquid nitrogen, and stored at $-80^{\circ} \mathrm{C}$. This protocol was used for all 3 experimental conditions and groups. Fish were also assessed for LOE throughout the study. Any fish that lost equilibrium was prodded with a net, and if they could not re-establish normal dorso-ventral orientation, it was removed and the time of LOE was recorded.

\subsubsection{Analytical techniques}

Ploidy was confirmed following the protocol outlined in Arumuganathan and Earle (1991) by using a FACSCalibur bench flow cytometer (BD Biosciences, California, USA). The triploidy induction protocol was $98 \%$ efficient. Plasma was used for analysis of ammonia, cortisol, sodium, and chloride. Frozen plasma was thawed and $10 \mu \mathrm{L}$ was removed for the analysis of ammonia. For all plasma ammonia samples, perchloric acid (8\%) was used to dilute the thawed plasma sample, and the sample was spun for 10 minutes at $18000 \mathrm{~g}$. The supernatant was 
removed and neutralized using $2 \mathrm{M} \mathrm{KHCO}_{3}$; the neutralized sample was spun again to remove the supernatant. Ammonia values were obtained using commercial kits (Sigma; Cat\#A0100), and use of the extinction coefficient of NADH at 340nm of $6,220 \mathrm{~L} / \mathrm{mol} \cdot \mathrm{cm}$. For sodium and chloride measurements, frozen plasma was thawed and $5 \mu \mathrm{L}$ of plasma was diluted 200 -fold in $\mathrm{dH}_{2} \mathrm{O}$. The diluted plasma sample was aliquoted into two separate tubes: (1) the aliquot was diluted an additional 6-fold followed by being run through a flame photometer (Varian AA240FS) (2) the aliquot of 200 -fold diluted plasma sample was mixed with $13 \mathrm{mM}$ mercuric thiocyanate and $0.5 \mathrm{M}$ ferric nitrate and was immediately read at $480 \mathrm{~nm}$ by spectrophotometer for the determination of plasma chloride. Plasma cortisol concentration was measured using a commercial enzyme-linked immunosorbent assay (ELISA) kit from Neogen Corporation (Lexington, KY). Due to the small size of fish used in this study only 10ul of plasma was available for steroid analysis. As a result, the initial step of the extraction process was modified and scaled down to use only $10 \mu \mathrm{l}$ of plasma dissolved in 100ul of ethyl ether. The rest of the protocol was carried out according to the manufacturer's specifications.

Liver and brain tissue was assessed for total ammonia. Briefly, sections of liver were weighed in micro-centrifuge tubes and sonicated in $8 \%$ perchloric acid using a micro ultrasonic cell disrupter (Kontes). The liver suspension was centrifuged at $18000 \mathrm{~g}$ for 10 minutes, and the supernatant was removed and neutralized in $2 \mathrm{M} \mathrm{KHCO}_{3}$. The neutralized sample was centrifuged again for the removal of the final neutralized supernatant. Brain samples were handled identically to liver samples with the exception of the neutralizing solution. To assist 
in buffering of the neutralization, 5M TRIS was used. To determine water content of the brain, portions of frozen brain tissue were allowed to thaw for 3 minutes before being placed on the scale for wet weights. After wet weights were recorded, samples were placed in an incubator at $55^{\circ} \mathrm{C}$. Dry weights were obtained after $24 \mathrm{~h}$ in the incubator, and the percent water and percent dry mass are presented here.

\subsubsection{Statistical analysis}

All data reported are mean values \pm SEM. Family was collapsed in the statistical analysis to focus on the effects of treatment, strain, and ploidy. In order to test for a significant effect of ploidy on time to LOE, I collapsed treatment and strain and perform an independent 2-group Mann-Whitney-U test. A three-way analysis of variance (ANOVA) was used on all physiological and biochemical measurements and treatment, ploidy, and strain were used as the fixed variables. If an interaction between fixed variables was seen to be significant, I collapsed non-significant variables, and performed two-way ANOVA, one-way ANOVA, and Tukey-post hoc tests. In the case of significant three-way interactions, a main effect was isolated and a two-way ANOVA was performed using the remaining main effects. Data was analyzed using R version 2.15.1. 


\subsection{Results}

\subsubsection{Loss of equilibrium}

A total of eight rainbow trout lost equilibrium in this study and they were all triploid (Figure 3.1). A Mann-Whitney-U test reveled a significant effect of ploidy on time to loss of equilibrium ( $\mathrm{p}=0.037$ ). The soft water high $\mathrm{pH}$ treatment resulted in two fish losing equilibrium, one Blackwater triploid and one Fraser Valley triploid. Half of the Carp Lake triploid fish lost equilibrium in the hard water high $\mathrm{pH}$ treatment.

\subsubsection{Plasma ions}

Three-way ANOVA revealed a significant effect of treatment ( $p=0.0002)$, but no effect of ploidy $(\mathrm{p}=0.135)$, strain $(\mathrm{p}=0.155)$, and no interaction between treatment and ploidy $(\mathrm{p}=0.11)$, treatment and strain $(\mathrm{p}=0.972)$, strain and ploidy $(\mathrm{p}=0.645)$, or strain, ploidy and treatment $(\mathrm{p}=0.789)$ on plasma sodium (Figure 3.2A). Compared with the soft water controls ( $\mathrm{pH}$ 6.7), exposure to $\mathrm{pH} 9.5$ resulted in a significant decrease in plasma sodium in both soft water $(\mathrm{p}=0.0002)$ and hard water $(\mathrm{p}=0.0003)$.

Three-way ANOVA yielded a significant effect of treatment $(\mathrm{p}<0.0001)$, and a strain effect ( $p=0.047)$, but no significant effect of ploidy $(p=0.145)$ on plasma chloride (Figure 3.2B). There was a significant interaction between treatment and ploidy $(\mathrm{p}=0.02)$, and no significant interaction between treatment and strain ( $\mathrm{p}=0.07)$, strain and ploidy $(\mathrm{p}=0.476)$, and strain, ploidy, and treatment $(\mathrm{p}=0.437)$. A 
tukey post-hoc test showed that the control diploid group was significantly elevated from the soft water diploid $(\mathrm{p}=0.03)$, triploid $(\mathrm{p}<0.0001)$, and the hard water diploid $(\mathrm{p}<0.0001)$, and triploid $(\mathrm{p}=0.001)$ high $\mathrm{pH}$ groups. The control triploid group was significantly elevated from the soft water triploid $(\mathrm{p}<0.0001)$, and the hard water diploid ( $\mathrm{p}<0.0001)$, and triploid $(\mathrm{p}=0.025)$ high $\mathrm{pH}$ groups.

\subsubsection{Plasma cortisol}

The three-way ANOVA revealed a significant effect of treatment $(\mathrm{p}<0.0001)$, and strain ( $\mathrm{p}=0.0005)$, with no significant effect of ploidy $(\mathrm{p}=0.917)$ on plasma cortisol (Figure 3.3). There was a significant interaction between treatment with ploidy and strain $(\mathrm{p}=0.034)$, treatment and strain $(\mathrm{p}=0.04)$, and no significant interaction between treatment and ploidy $(\mathrm{p}=0.788)$, and strain and ploidy $(\mathrm{p}=0.74)$ with cortisol as well. Isolating the diploid groups, there is a significant increase in soft high pH Blackwater plasma cortisol compared to the control Blackwater group $(p=0.018)$, Carp Lake group $(p=0.0006)$, Fraser Valley group $(p=0.0007)$, the soft water high $\mathrm{pH}$ Pennask ( $\mathrm{p}=0.025)$, and the hard water high $\mathrm{pH}$ Fraser valley group $(\mathrm{p}=0.02)$. Isolating the triploid groups, a significant increase of plasma cortisol occurs in the hard water high pH Blackwater group compared to the control Blackwater $(\mathrm{p}=0.01)$, Carp Lake $(\mathrm{p}=0.025)$, and the hard water high $\mathrm{pH}$ Pennask group ( $\mathrm{p}=0.011)$. 


\subsubsection{Ammonia and brain weights}

Three-way ANOVA revealed a significant effect of high pH treatment $(\mathrm{p}<0.0001)$, and no significant effect of ploidy $(\mathrm{p}=0.316)$, and strain $(\mathrm{p}=0.086)$ on plasma ammonia in the rainbow trout. There was no significant interaction between treatment and ploidy $(\mathrm{p}=0.666)$, treatment and strain $(\mathrm{p}=0.448)$, strain and ploidy $(\mathrm{p}=0.803)$, and strain, ploidy and treatment $(\mathrm{p}=0.39)$. All groups experienced a 4fold increase in plasma ammonia in both the hard water and soft water treatment (Figure 3.4A).

Three-way ANOVA demonstrated that there was no significant effect of treatment $(p=0.1459)$, ploidy $(p=0.399)$, and strain $(p=0.318)$ on liver ammonia. There were no significant interactions between treatment and ploidy $(\mathrm{p}=0.839)$, treatment and strain $(\mathrm{p}=0.95)$, strain and ploidy $(\mathrm{p}=0.179)$, and strain, ploidy, and treatment $(p=0.788)$ on liver ammonia. Liver ammonia was stable throughout all groups regardless of exposure treatment (Figure 3.4B).

A three-way ANOVA revealed a significant effect of treatment $(\mathrm{p}<0.0001)$, ploidy $(\mathrm{p}=0.035)$, and strain $(\mathrm{p}=0.013)$ on brain ammonia. There were no significant interactions between treatment and ploidy $(\mathrm{p}=0.06)$, treatment and strain $(\mathrm{p}=0.179)$, strain and ploidy $(\mathrm{p}=0.36)$, and strain, ploidy and treatment $(\mathrm{p}=0.954)$. High pH produced a 2.5 fold increase in brain ammonia from control values (Figure $3.4 \mathrm{C})$.

Brain dry weights and water content did not vary across conditions with a three way ANOVA showing no significant effect of treatment $(\mathrm{p}=0.776)$, ploidy $(p=0.21)$, and strain $(p=0.31)$ (Figure 3.5A and 3.5B). There were no significant 
interactions between treatment and ploidy $(\mathrm{p}=0.11)$, treatment and strain $(\mathrm{p}=0.971)$, strain and ploidy $(\mathrm{p}=0.645)$, and strain, ploidy, and treatment $(\mathrm{p}=0.789)$.

\subsection{Discussion}

The results of this study suggest that water hardness does not affect the physiological responses of trout to $\mathrm{pH} 9.5$ exposures. A total of 8 trout showed LOE over the $24 \mathrm{~h}$ of exposure to high $\mathrm{pH}$ water (Figure 3.1) and 6 of the 8 fish that lost equilibrium were exposed to $\mathrm{pH} 9.5$ in hard water. These results are in contrast to those of Yesaki and Iwama (1992) who observed no deaths during 24h exposure to pH 10.1 in hard water $\left(\left[\mathrm{CaCO}_{3}\right]=320 \mathrm{mg} / \mathrm{L}\right)$, but had $28.5 \%$ mortality in the trout exposed to $\mathrm{pH} 10.1$ in soft water. Also, Wilson et al. (1998) did not observe any mortality in trout exposed to $\mathrm{pH} 10.0$ for 15 days in soft $\left(\left[\mathrm{CaCO}_{3}\right]=4 \mathrm{mg} / \mathrm{L}\right)$ or hard $\left(\left[\mathrm{CaCO}_{3}\right]=320 \mathrm{mg} / \mathrm{L}\right)$ water. Clearly there is large study-to-study variation in high $\mathrm{pH}$ tolerance in trout. Fish size may be one factor contributing to the variation in high pH tolerance among studies. Compared to this study, Yesaki and Iwama (1992) and Wilson et al. (1998) used trout weighing over 400g and 200g, respectively, while I used juvenile trout weighing no more than $12 \mathrm{~g}$. Weight has been shown to be an advantage as larger fish have been shown to have less stress-induced sodium loss as shown following injection of adrenaline (McDonald and Milligan, 1997), and have shown a greater capacity to adjust to seawater transfer (McCormick and Naiman, 1984). Smaller fish are expected to experience greater osmotic stress as a result of their larger gill surface area to total body mass (McDonald and Milligan, 1997). 
Clearly, future studies should focus on the effects of body mass on high $\mathrm{pH}$ tolerance in trout.

Apart from increasing survival in high $\mathrm{pH}$ water, the addition of divalent ions to the water was expected to limit ion loss across the gill. In the study by Yesaki and Iwama (1992) exposure of trout to hard $\left(\left[\mathrm{CaCO}_{3}\right]=320 \mathrm{mg} / \mathrm{L}\right) \mathrm{pH} 10.1$ water resulted in fewer ionic disturbances than in trout exposed to $\mathrm{pH} 10.1 \mathrm{in}$ soft water $\left(\left[\mathrm{CaCO}_{3}\right]=\right.$ 4mg/L). Plasma sodium and chloride concentrations significantly decrease as a result of high $\mathrm{pH}$ exposure (Figure 3.2A and 3.2B), but there was no affect of water hardness on plasma ion concentrations. Remodeling of the gill to a soft water environment in fish has been shown to take numerous days (McDonald and Rogano, 1986; Greco et al. 1996), and 24h may not be sufficient time for the rainbow trout to interact with hard water as long-term exposure to hard water has been shown to limit ion loss to the environment (McDonald and Robinson, 1993; McDonald and Milligan, 1997).

Cortisol is a stress hormone that has been shown to increase the capacity for gill ion regulation by proliferating gill chloride cells (Laurent and Perry, 1990; Laurent et al. 1994), and increasing the activity of $\mathrm{Na}^{+} / \mathrm{K}^{+}$ATPase in trout (Seidelin et al. 1999) and salmon (Shrimpton et al. 1994; Shrimpton and McCormick, 1999). Overall, a significant increase in plasma cortisol occurs as a result of high $\mathrm{pH}$ exposure, which correlates with the ionoregulatory challenge the trout experienced. The change in cortisol in this study is not consistent across treatments, with no decreased production of plasma cortisol as a result of exposure to hard high $\mathrm{pH}$ water (Figure 3.3). Yesaki and Iwama (1992) showed that there was a doubling of 
plasma cortisol by $96 \mathrm{~h}$ in their soft water high $\mathrm{pH}$ exposure compared to a stable level of cortisol in hard water high $\mathrm{pH}$ exposed fish. The continued increase in plasma cortisol was most likely exacerbated by the continuing decrease of plasma ions in their soft water trout (Yesaki and Iwama, 1992). However, their results showed no significant difference between treatments at the $24 \mathrm{~h}$ time point, similar to the results presented here.

My study showed no differences between soft and hard water in terms of ammonia accumulation in high $\mathrm{pH}$. Hard water has been shown to improve the excretion rate of ammonia across the gill (Yesaki and Iwama, 1992; Wilson et al. 1998), and was expected to limit ammonia accumulation in the plasma, liver, and brain tissue. Plasma ammonia, however, increases 3-fold after $24 \mathrm{~h}$ in both high $\mathrm{pH}$ conditions (Figure 3.4A). This is consistent with other studies (Wilkie and Wood, 1991; Wilkie et al. 1994; Wilson et al. 1994; McGeer and Eddy, 1998), but does not demonstrate a benefit of hard water. Liver ammonia also did not change in any condition during the exposure (Figure 3.4B), which is in contrast to the result obtained by Wilson et al. (1998), who demonstrated a significant doubling of liver ammonia in soft water ( $\mathrm{pH} 10)$. Wilson et al. (1998) reported that their rainbow trout were capable of maintaining control levels of brain ammonia throughout their high $\mathrm{pH}$ exposure. The 3 -fold increase in brain ammonia I report in this study is consistent with the trend presented in the previous experiment (Chapter 2). The significant 3-fold increase in brain ammonia (Figure 3.4C) as a result of high $\mathrm{pH}$ exposure indirectly suggests that protective metabolites such as glutamine are being produced. An immediate increase in brain glutamine occurs in conjunction with an 
increase in ammonia (Sanderson et al. 2010; Chapter 2), in an apparent attempt to protect the brain from a lethal ammonia load. The brain water content suggests that while the metabolite concentration rises the organism maintains the osmolarity of the brain (Figure 3.5A). Rainbow trout have been shown to accumulate water in response to a high level of external ammonia (Sidhu, 2012), and increased water content may have resulted in increased cranial pressure and mortality. However, water content of the brain does not increase with high $\mathrm{pH}$ exposure, suggesting that the brain does not swell in response to high pH water (Figure 3.5A).

There was a significant effect of ploidy on LOE during high pH exposure (both soft water and hard water combined; Figure 3.1). Across all measurements, only brain ammonia accumulation at high $\mathrm{pH}$ showed a ploidy effect with diploid trout having lower brain ammonia than triploid trout (Figure 3.4C), suggesting, albeit tentatively, a link between the increased LOE in triploid trout at high $\mathrm{pH}$ and brain ammonia accumulation. However, the levels of ammonia in the brain tissue of triploids are lower than the values obtained from my previous study (Chapter 2) and those obtained during exposure to high external ammonia (Sanderson et al. 2010), suggesting that despite the difference brain ammonia results are within physiologically manageable levels.

Comparing this study to my previous work shows that there is great year-toyear variation in high $\mathrm{pH}$ tolerance, as we did not observe a significant strain effect in the present study yet a significant ploidy effect is obtained that was absent in previous experiments (Chapter 2). The previous study demonstrated a pronounced sensitivity of rainbow trout to high $\mathrm{pH}$ water, with the domesticated Fraser Valley 
strain outperforming wild strains in terms of duration to high $\mathrm{pH}$ exposure (Chapter 2). The Fraser Valley strain saw limited LOE in a multi-day high pH (9.5) exposure over consecutive years, while all wild strains began to lose equilibrium hours into each assessment (Chapter 2). Individual trout begin to lose equilibrium within $24 \mathrm{~h}$ into this study, but the Fraser Valley strain does not exhibit the same tolerance I noted in previous years. Domestication has been shown to benefit trout in terms of limiting cortisol production in high stress environments (Woodward and Strange, 1987), and although I report a significant strain effect in my fish in regards to plasma cortisol, only the Blackwater strain is significantly elevated from the Fraser Valley domesticated strain in the soft water high $\mathrm{pH}$ treatment.

\subsection{Conclusions}

Hard water did not significantly reduce ammonia accumulation, the production of cortisol, or limit ion loss to the environment. Furthermore, hard water provided no benefit in terms of time to LOE amongst the rainbow trout used in this study. Given the immediate exposure of the trout to the environment, an adjustment period may be required to fully take advantage of the water chemistry. However, this is similar to what the trout would experience during lake stocking, suggesting that the immediate exposure may be lethal. A longer-term study would be required for the effect that hard water evokes on the survival of the trout, and is warranted, as many lakes in $\mathrm{BC}$ possess nearly double the hardness $\left(\mathrm{as}^{\mathrm{CaCO}} 3\right)_{3}$ used in this study. I note that there is a ploidy effect of high $\mathrm{pH}$ water in my trout, one that was not present in previous years. The outright cause of increased LOE in triploid fish is 
unknown, but is unlikely to be a result of the physiological measurements made here. 


\section{Figures}

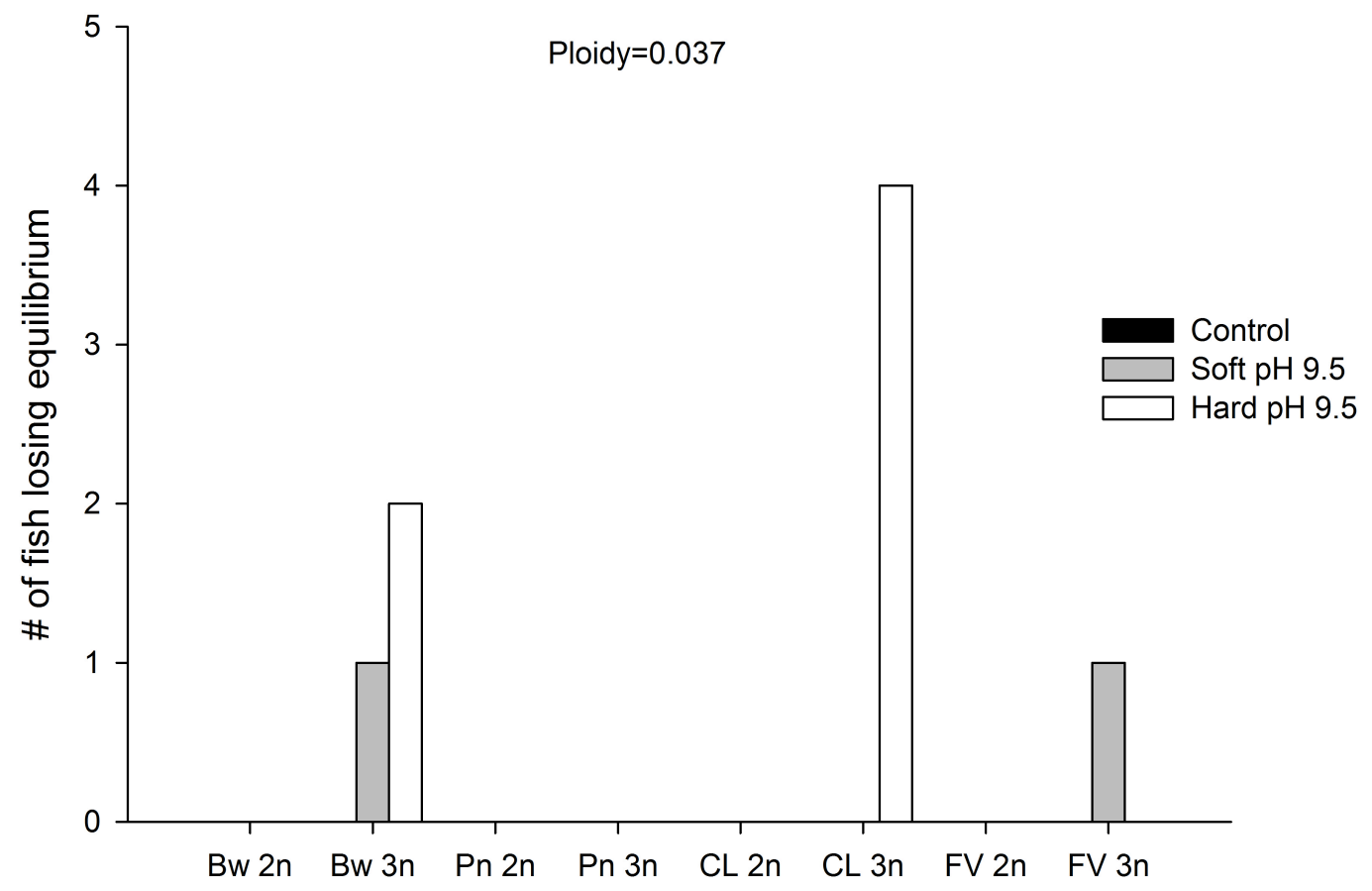

Figure 3.1: Number of fish showing a loss of equilibrium over 24h exposure to soft water at pH 6.7 (control; black bars), soft water at pH 9.5 (soft pH 9.5; grey bars) and hard water at pH 9.5 (hard pH 9.5; open bars). Blackwater (Bw), Pennask (Pn), Carp Lake (CL), and Fraser Valley (FV) strains as both diploids (2n) and triploids (3n). P values from significant main effects are denoted on figure. 

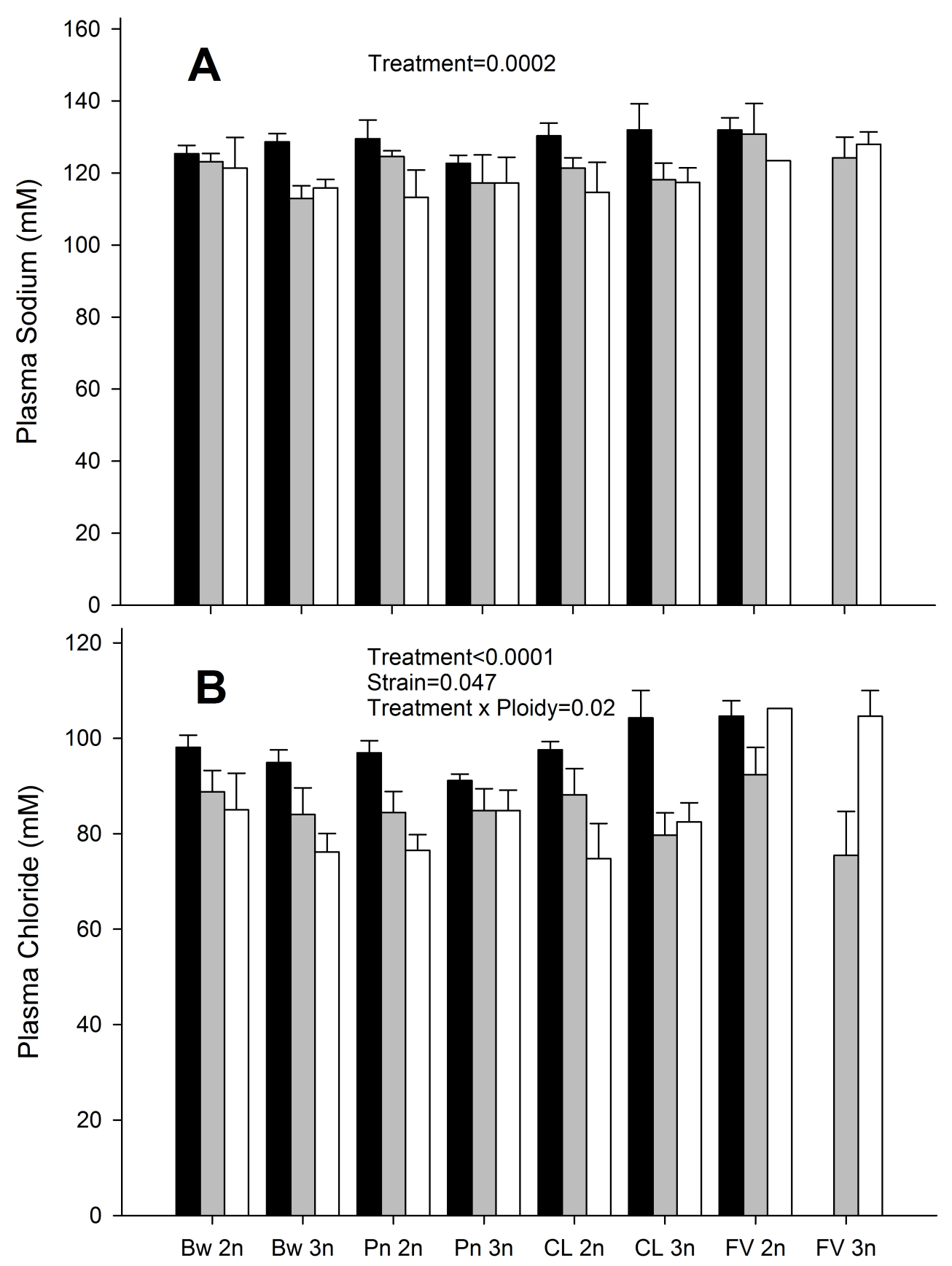

Figure 3.2: Plasma sodium (A) and chloride (B) in the Blackwater (Bw), Pennask (Pn), Carp Lake (CL), and Fraser Valley (FV) strains, as both diploid (2n) and triploid (3n), exposed for $24 \mathrm{~h}$ to soft water at $\mathrm{pH} 6.7$ (controls; black bars), soft water at $\mathrm{pH}$ 9.5 (grey bars), and hard water at $\mathrm{pH} 9.5$ (open bars) (n=6-8 for all groups except for the CL $3 n(n=4)$ and FV groups $(n=1-4))$. P values from significant main effects and interactions are denoted on figure. 


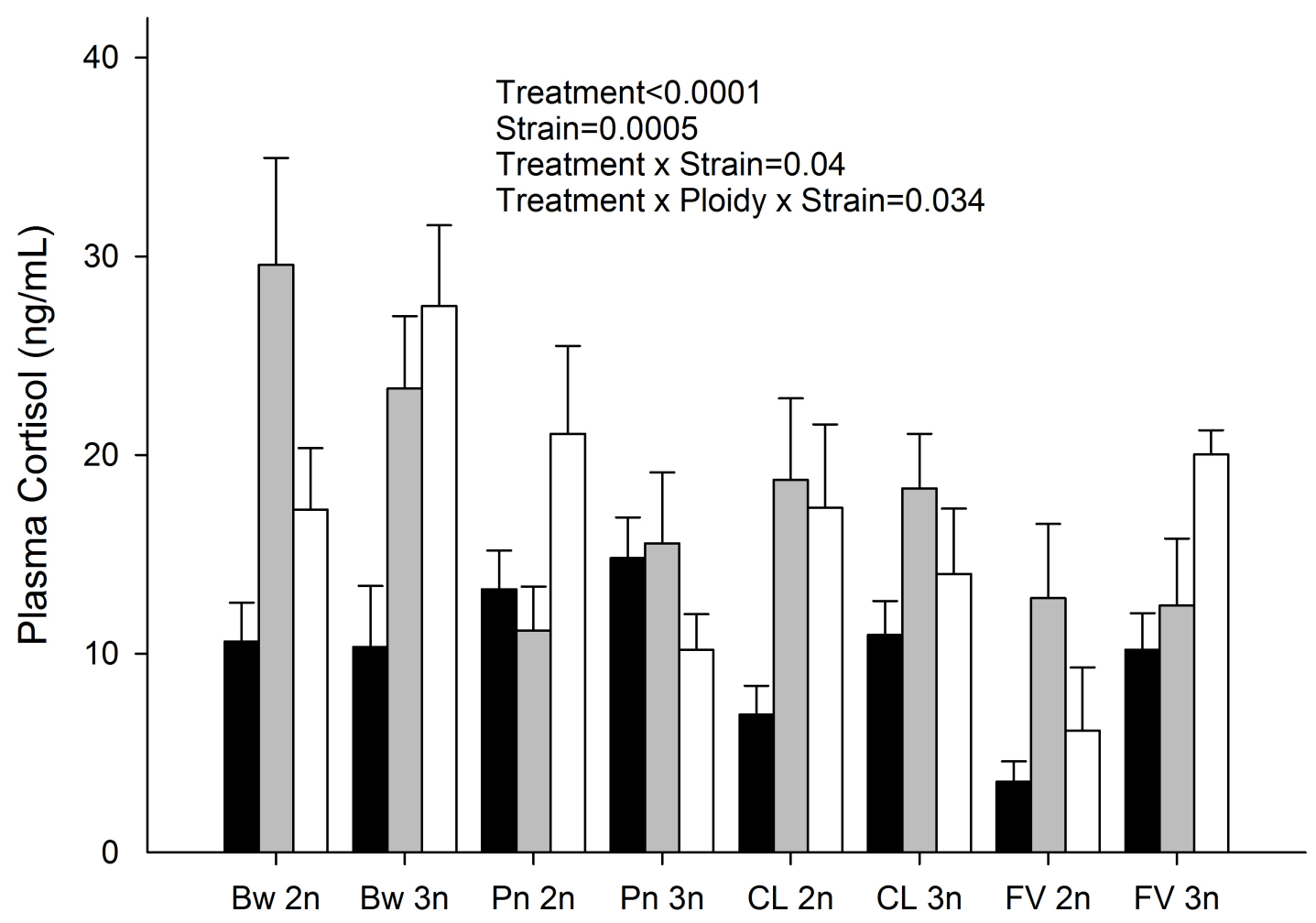

Figure 3.3: Total plasma cortisol in the Blackwater (Bw), Pennask (Pn), Carp Lake (CL), and Fraser Valley (FV) strains, as both diploid (2n) and triploid (3n), exposed for $24 \mathrm{~h}$ to soft water at $\mathrm{pH} 6.7$ (controls; black bars), soft water at $\mathrm{pH} 9.5$ (grey bars), and hard water at $\mathrm{pH} 9.5$ (open bars) ( $\mathrm{n}=6-8$ for all groups except for the CL $3 n(n=4)$ and FV groups $(n=2-4))$. P values from significant main effects and interactions are denoted on figure. 

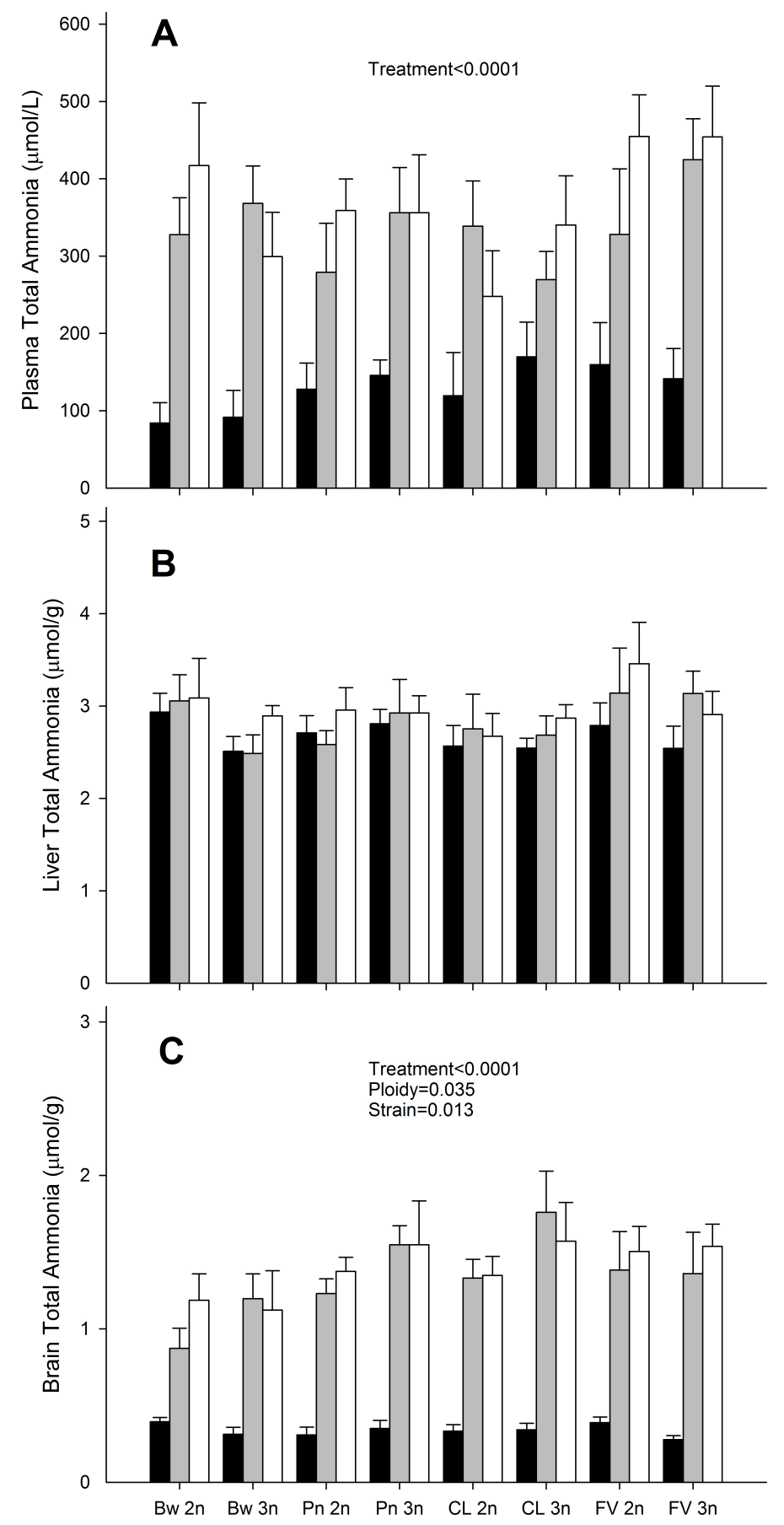

Figure 3.4: Total ammonia in the plasma (A), liver (B), and brain (C) in the Blackwater (Bw), Pennask (Pn), Carp Lake (CL), and Fraser Valley (FV) strains, as both diploid (2n) and triploid (3n), exposed for $24 \mathrm{~h}$ to soft water at $\mathrm{pH} 6.7$ (controls; black bars), soft water at pH 9.5 (grey bars), and hard water at pH 9.5 (open bars) ( $n=6-8$ for all groups except for the CL $3 n(n=4))$. P values from significant main effects and interactions are denoted on figure. 

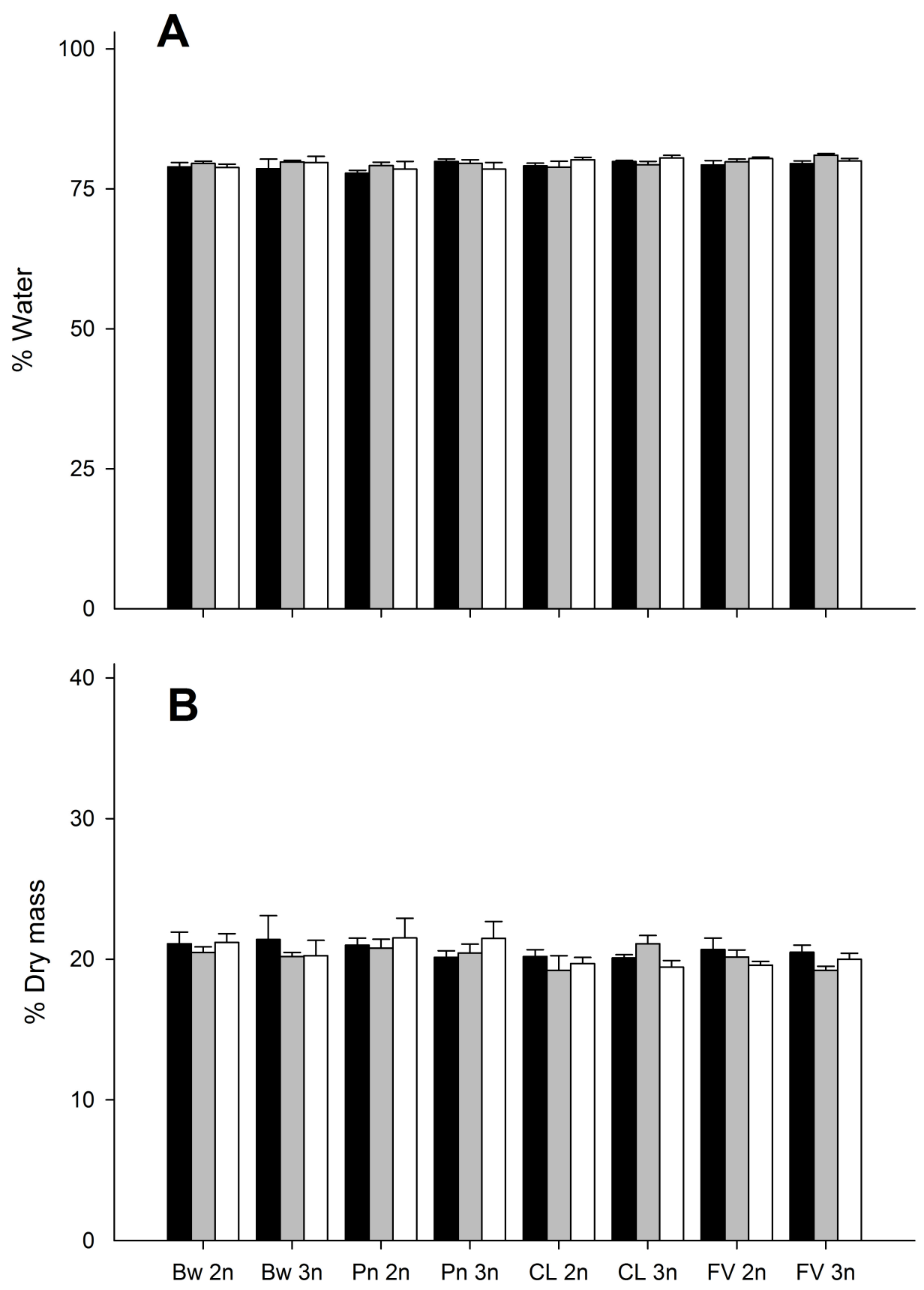

Figure 3.5: Percent composition of the brain in terms of water (A) and dry mass (B) in the Blackwater (Bw), Pennask (Pn), Carp Lake (CL), and Fraser Valley (FV) strains, as both diploid (2n) and triploid ( $3 n$ ), exposed for $24 \mathrm{~h}$ to soft water at $\mathrm{pH}$ 6.7 (controls; black bars), soft water at pH 9.5 (grey bars), and hard water at pH 9.5 (open bars) ( $n=6-8$ for all groups except for the CL $3 n(n=4))$. 


\section{[4] General Discussion}

4.1 The effects of strain and ploidy on the physiological response of trout to $\mathrm{pH} 9.5$ water

The results suggest that among all the trout strains examined in this study, the Fraser Valley domesticated strain is best suited for stocking to high pH lakes. In 2011 and 2012 the Fraser Valley domesticated strain showed significantly less LOE in pH 9.5 water (Figure 2.1; Figure 2.3) compared with the wild strains of trout investigated in this study. The most dramatic difference between strains occurred in my first experiment in 2011 (Figure 2.1), with more than 30\% of wild strains losing equilibrium within the first $12 \mathrm{~h}$ exposure to $\mathrm{pH} 9.5$ and over $80 \%$ of wild strains losing equilibrium by $24 \mathrm{~h}$. Due to the variation in the results between years I cannot conclusively state whether ploidy affects high $\mathrm{pH}$ tolerance. In the 2013 study, all fish that lost equilibrium were triploid, with no diploid fish succumbing to high $\mathrm{pH}$ in the 24h experiment. However, the 2011 and 2012 studies showed no difference in loss of equilibrium between the ploidies.

Each year used a slightly different exposure protocol to increase $\mathrm{pH}$ to 9.5 (2011 6h gradual increase in pH; 2012 1h gradual increase in pH; 2013 immediate transfer), but the trout consistently exhibited sensitivity to high $\mathrm{pH}$. My finding that high $\mathrm{pH}$ elicits an extreme response is in contrast to various other studies (Wilkie and Wood, 1991; Wilkie et al. 1996; Wilson et al. 1998), which instead show that rainbow trout are capable of prolonged survival in high $\mathrm{pH}$. As discussed in chapter 2 , various other factors play a role in determining tolerance in a high $\mathrm{pH}$ medium. 
Very few conditions overlap across studies as many use larger organisms, performed their experiments in different seasons, had remarkably different rearing conditions, and used brood stocks of rainbow trout from very different environments (Wright and Wood, 1985; Yesaki and Iwama, 1992; Wilson et al. 1994; Wilkie et al. 1996; Wilson et al. 1998; Laurent et al. 2000; Wood and Nawata, 2011).

The exposure to a high $\mathrm{pH}$ environment caused the retention of ammonia in various tissues across the body, and changes in ion levels of the rainbow trout, but there were no physiological disturbances that were different between domestic and wild fish. All fish experienced increases in plasma ammonia (Figure 2.3A; Figure 3.4A), brain ammonia (Figure 2.5A; Figure 3.4C) brain glutamine (Figure 2.5C), and plasma lactate (Figure 2.6C), with decreases in brain glutamate (Figure 2.5B), plasma sodium (Figure 3.2A), and plasma chloride (Figure 2.6B; Figure 3.2A). All these changes are within physiological levels that have previously been reported. My values for ammonia accumulation in plasma and tissues are similar to those seen in the literature (Wilkie and Wood, 1994; Wilkie and Wood, 1995; Wilson et al. 1998; Wang et al. 2003; Zimmer et al. 2013), with glutamate, and glutamine levels well within those reported in high ammonia studies (Arillo et al. 1981; Sanderson et al. 2010). There is a significant increase in brain ammonia across triploids coinciding with the increased LOE of triploid fish in the 2013 study, but the values measured were lower than those collected in groups from the 2012 study and are half of what has been noted in high external ammonia studies (Sanderson et al. 2010). It should be noted that the ion levels presented in this study are below what 
is commonly seen in literature (Wood and Randall, 1973; Wilkie et al. 1999). Given the remarkably soft water used in the rearing conditions $(<17.9 \mathrm{mg} / \mathrm{L})$ a loss of plasma ions is not surprising as a result of ions leaking out across the gill to the hypo-osmotic environment (Mcdonald and Rogano, 1986). This could result in the subsequent establishment of a lower steady-state condition. The physiological measurements made in chapters 2 and 3 were chosen because previous studies had indicated that they were most affected by high $\mathrm{pH}$ exposures. The results suggest that the Fraser Valley strain is more tolerant of high $\mathrm{pH}$, and that the wild strains are more sensitive to high $\mathrm{pH}$ water, but no physiological measurement yielded a clear difference between domestic and wild fish. As I only sampled surviving fish, my measurements cannot elucidate the underlying cause of LOE in high $\mathrm{pH}$.

\subsection{The effects of water hardness on the physiological response to high $\mathrm{pH}$ water of various strains and ploidies of rainbow trout}

Exposure to hard water did not change the physiological response of any strain or ploidy to high $\mathrm{pH}$ water. All groups experienced significant increases in plasma and brain ammonia, and significant decreases in plasma sodium and chloride. The most notable outcome of the hard water exposure was the significant effect of ploidy on high $\mathrm{pH}$, as presented in the LOE data. The only trout to lose equilibrium throughout the high $\mathrm{pH}$ exposure were triploid, and this corresponded to a significant accumulation of brain ammonia. Originally I assumed that hard water exposed fish would exhibit an advantage over soft water exposed fish during high pH exposure because of the previous work done by Yesaki and Iwama (1992). 
However, the results presented here suggest that all physiological changes are a result of high $\mathrm{pH}$ exposure rather than hard water.

\subsection{Recommendations and future research}

Despite the results suggesting that the Fraser Valley strain show greater $\mathrm{pH}$ tolerance, I do not believe they would be an effective strain to stock in the wild. While the Fraser Valley have proven to be rather successful in lab trials (Scott, 2012; Chapter 2) the translation to high performance in the wild setting has been disappointing. As mentioned earlier, domestication has been shown to be advantageous in exposures to abiotic stressors in trout (Woodword and Strange, 1987; Lepage et al. 2001; Scott, 2012), theorized to be due to a reduced cortisol response post-stress (Woodward and Strange, 1987; Pottinger and Carrick, 1999). Domestication selects for growth rate and size and often performs poorly in the wild (Brauhn and Kincaid, 1982; Huntingford, 2004; Araki et al. 2008) as a result of their increased aggression and risk taking behavior (Vincent, 1960; Johnsson and Abrahams, 1991; Biro et al. 2004). The domesticated strain performance in this study may be an artifact of generations in aquaculture, adjusting to confined quarters, multiple handlings, and sudden changes in water parameters.

Crosses with the Fraser Valley strain may potentially enhance the capability of wild strains to environmental extremes, or reduce their survival by alteration of a phenotype that has been selected for by nature.

I would recommend the implementation of a process that selects individuals amongst the wild strains that exhibit greater tolerance of a high $\mathrm{pH}$ environment. 
My LOE observations demonstrate that there are individuals that are capable of surviving for extended periods of time in high $\mathrm{pH}$, and selecting for these organisms may yield offspring that are also high $\mathrm{pH}$ tolerant. However, this warrants future work in determining if $\mathrm{pH}$ tolerance is genetically heritable. Another facet of tolerance may be exposure time, or acclimation time. Pre-exposure to reasonably high $\mathrm{pH}$ ( 8.0 and above) may allow the organism time to adjust physiologically to a pH a magnitude higher in lake settings (Wilkie and Wood, 1994; Wilkie and Wood, 1995; Wilkie et al. 1996). The change from the holding conditions (pH 6.7) to the experimental pH (9.5) may have been the cause of fish losing equilibrium in my study.

Future studies should be geared towards studying the effects of long-term exposure to high $\mathrm{pH}$. All the studies presented in this thesis are limited in duration, with the longest exposure lasting $72 \mathrm{~h}$. With lakes in $\mathrm{BC}$ expected to reach a $\mathrm{pH}$ of 9.5, exploring whether or not stocked strains are capable of adjusting to a high $\mathrm{pH}$ in the long-term is paramount. Lahontan cutthroat trout exposed to highly alkaline lake water ( $\mathrm{pH}$ 9.4) for two years experienced a suite of changes to adjust long-term, with increases in chloride cell density, plasma ammonia, and internal pH (Wilkie et al. 1994). In the 2012 study, the number of fish losing equilibrium is limited after $24 \mathrm{~h}$, suggesting that there is a critical period of adjustment, and that there are individuals in these stocks capable of greater high $\mathrm{pH}$ tolerance. A potential experiment would be to run a larger group of trout in a high $\mathrm{pH}$ exposure over 6 months, with measurements directed to ammonia and ion balance. One could hypothesize that fish capable of surviving longer in a high $\mathrm{pH}$ environment would 
have similar histological and physiological changes as those seen in Lahontan cutthroat trout. 


\section{References}

Allen, S. K., \& Stanley, J. G. (1979). Polyploid Mosaics Induced by Cytochalasin B in Landlocked Atlantic Salmon, Salmo salar. Transactions of the American Fisheries Society, 108(5), 462-466.

Anderson, P. M. (2001). Urea and glutamine synthesis: environmental influences on nitrogen excretion. Fish Physiology, 20, 239-277.

Araki, H., Berejikian, B. A., Ford, M. J., \& Blouin, M. S. (2008). Fitness of hatcheryreared salmonids in the wild. Evolutionary Applications, 1(2), 342-355.

Arillo, A., Margiocco, C., Melodia, F., Mensi, P., \& Schenone, G. (1981). Ammonia Toxicity Mechanism in Fish: Studies on Rainbow Trout (Salmo gairdneri rich.). Exotoxicology and Environmental Safety, 5, 316-328.

Arumuganathan, E., \& Earle, E. D. (1991). Nuclear DNA content of some important plant species. Plant Molecular Biology Reporter, 9(3), 208-218.

Avella, M., Masoni, A., Bornancin, M., \& Mayer-Gostan, N. (1987). Gill morphology and sodium influx in the rainbow trout (Salmo gairdneri) acclimated to artificial freshwater environments. Journal of Experimental Zoology, 241(2), $159-169$.

Beatty, R. A. (1970). The Genetics of the Mammalian gamete. Biological Reviews, 45(1), 73-117.

Behnke, R. J. (1972). The rationale for preserving genetic diversity: examples of the utilisation of intraspecific races of salmonid fishes in fisheries management. Proceedings of the Annual Conference Western Association of State Game and 
Fish Commissioners, 52, 559-561.

Behnke, R. J. (1979). The native trouts of the genus Salmo of western North America. Report to US Fish and Wildlife Service, Denver, Colorado.

Benhke, R. J. (2010). Trout and salmon of North America. Simon and Schuster.

Bergmeyer, H. U. (1983). Methods of Enzymatic Analysis. New York: Academic Press.

Biro, P. A., Abrahams, M. V., Post, J. R., \& Parkinson, E. A. (2004). Predators select against high growth rates and risk-taking behaviour in domestic trout populations. Proceedings of the Royal Society of London B: Biological Sciences, 271(1554), 2233-2237.

Blanc, J. M., Poisson, H., \& Vallee, F. (1992). Survival, growth and sexual maturation of the triploid hybrid between rainbow trout and arctic char. Aquatic Living Resource, 5, 15-21.

Blaxhall, P. C., \& Daisley, K. W. (1973). Routine haematological methods for use with fish blood. Journal of Fish Biology, 5(6), 771-781.

Brauhn, J. L., \& Kincaid, H. (1982). Survival, Growth, and Catchability of Rainbow Trout of Four Strains. North American Journal of Fisheries Management, 2(1), $1-10$.

Cameron, J. N., \& Heisler, N. (1983). Studies of ammonia in the rainbow trout: physio-chemical parameters, acid-base behaviour and respiratory clearance. Journal of Experimental Biology, 105(1), 107-125.

Chourrout, D. (1984). Pressure-induced retention of second polar body and suppression of first cleavage in rainbow trout: Production of all-triploids, alltetraploids, and heterozygous and homozygous diploid gynogenetics. 
Aquaculture, 36(1-2), 111-126.

Clarke, A. 2012. Rainbow trouts strains stocked in British Columbia: matching fish charateristics with habitat to maximize fishing quality. BCO Sport Fishing. 69: $20-26$

Cuellar, O., \& Uyeno, T. (1972). Triploidy in rainbow trout. Cytogenetics, 11, 508515.

Daye, P. G., \& Garside, E. T. (1975). Lethal levels of pH for brook trout, Salvelinus fontinalis (Mitchill). Canadian Journal of Zoology, 53, 639-641.

Daye, P. G., \& Garside, E. T. (1976). Histopathologic changes in surficial tissues of brook trout, Salvelinus fontinalis (Mitchill), exposed to acute and chronic levels of pH. Canadian Journal of Zoology, 54, 2140-2155.

Depeche, J., Gilles, R., Daufresne, S., \& Chiapello, H. (1979). Urea content and urea production via the ornithine-urea cycle pathway during the ontogenic development of two teleost fishes. Comparative Biochemistry and Physiology Part A: Physiology, 63(1), 51-56.

DiBattista, J. D., Anisma, H., Whitehead, M., \& Gilmour, K. M. (2005). The effects of cortisol administration on social status and brain monoaminergic activity in rainbow trout, Oncorhynchus mykiss. The Journal of Experimental Biology, $208,2707-2718$.

Dillon, J. C., Schill, D. J., \& Teuscher, D. M. (2000). Relative Return to Creel of Triploid and Diploid Rainbow Trout Stocked in Eighteen Idaho Streams. North American Journal of Fisheries Management, 20, 1-9.

Dunn, H. O., McEntee, K., \& Hansel, W. (1970). Diploid-triploid chimerism in a bovine 
true hermaphrodite. Cytogenetic and Genome Research, 9(4), 245-259.

Eddy, F. B. (1975). The effect of calcium on gill potentials and on sodium and chloride fluxes in the goldfish, Carassius auratus. Journal of Comparative Physiology, 96(2), 131-142.

Eddy, F. B. (1976). Acid-base balance in rainbow trout (Salmo gairdneri) subjected to acid stresses. The Journal of Experimental Biology, 64, 159-171.

Emerson, K., Russo, R. C., Lund, R. E., \& Thurston, R. V. (1975). Aqueous Ammonia Equilibrium Calculations: Effect of $\mathrm{pH}$ and Temperature. Journal of the Fisheries Research Board of Canada, 32(12), 2379-2383.

Evans, D. H. (2011). Freshwater Fish Gill Ion Transport: August Krogh to morpholinos and microprobes. Acta Physiologica, 202, 349-359.

Evans, D. H., Piermarini, P. M., \& Choe, K. P. (2005). The Multifunctional Fish Gill: Dominant Site of Gas Exchange, Osmoregulation, Acid-Base Regulation, and Excretion of Nitrogenous Waste. Physiological Review, 85, 97-177.

Evans, D. H., Piermarini, P. M., \& Potts, W. T. W. (1999). Ionic Transport in the Fish Gill Epithelium. Journal of Experimental Zoology, 283, 641-652.

Fechheimer, N. S., Isakova, G. K., \& Belyaev, D. K. (1983). Mechanisms involved in the spontaneous occurrence of diploid-triploid chimerism in the mink (Mustela vison) and chicken (Gallus domesticus). Cytogenetic and Genome Research, 35(4), 238-243.

Felip, A., Carrillo, M., Herraez, M. P., Zanuy, S., \& Basurco, B. (2009). Protocol F Induction of triploidy by cold shock [Pratical guide of protocols: chromosome set manipulation]. Mediterranean Options: Series B. Studies and Research, 63, 
43-48.

Ferguson, R. A., Kieffer, J. D., \& Tufts, B. L. (1993). The effects of Body Size on the Acid-Base and Metabolite Status in the white Muscle of Rainbow trout before and after exhaustive exercise. Journal of Experimental Biology, 180, 195-207.

Fevolden, S. E., Refstie, T., \& Roed, K. H. (1991). Selection for high and low cortisol stress response in Atlantic salmon (Salmo salar) and rainbow trout (Oncorhynchus mykiss). Aquaculture, 95(1-2), 53-65.

Freshwater Fisheries Society of British Columbia. 2004. Rainbow trout strains currently stocked in BC waters.

Galbreath, P. F., St. Jean, W., Anderson, V., \& Thorgaard, G. H. (1994). Freshwater performance of all-female diploid and triploid Atlantic salmon. Aquaculture, $128,41-49$.

Gillet, C., Vauchez, C., \& Haffray, P. (2001). Triploidy induced by pressure shock in Arctic char (Salvelinus alpinus): growth, survival and maturation until the third year. Aquatic Living Resources, 14(5), 327-334.

Goss, G. G., Perry, S. F., Fryer, J. N., \& Laurent, P. (1998). Gill Morphology and AcidBase Regulation in Freshwater Fishes. Comparative Biochemistry and Physiology, 119(1), 107-115.

Goss, G. G., \& Wood, C. M. (1990). $\mathrm{Na}^{+}$and $\mathrm{Cl}^{-}$Uptake Kinetics, Diffusive Effluxes and Acidic Equivalent Fluxes Across the Gills of Rainbow Trout: 1. Responses to Environmental Hyperoxia. The Journal of Experimental Biology, 152, 521-547.

Greco, A. M., Fenwick, J. C., \& Perry, S. F. (1996). The effects of soft-water acclimation on gill structure in the rainbow trout Oncorhynchus mykiss. Cell and Tissue 
Research, 285, 75-82.

GSGislason \& Associates Ltd. 2009. Freshwater Sport Fishing in British Columbia: Sending Ripples through the Provincial Economy.

Guo, X., Hershberger, K. M., \& Myers, J. M. (1990). Growth and Survival of Intrastrain and Interstrain Rainbow Trout (Oncorhynchus mykiss) Triploids. Journal of the World Aquaculture Society, 21(4), 250-256.

Handy, R. D. (1989). The ionic composition of Rainbow trout body mucus. Comparative Biochemistry and Physiology, 93A(3), 571-575.

Hansen, P. J. (2002). Effect of high pH on the growth and survival of marine phytoplankton: implications for species succession. Aquatic Microbial Ecology, 28(3), 279-288.

Hardy, R. W. (2002). Rainbow trout, Oncorhynchus mykiss.

Heisler, N. (1989). Acid-Base regulation in fishes. 1. Mechanisms. Acid Toxicity and Aquatic Animals, 85-97.

Heming, T. A., \& Blumhagen, K. A. (1988). Plasma acid-base and electrolyte states of rainbow trout exposed to alum (aluminum sulphate) in acidic and alkaline environments. Aquatic toxicology, 12(2), 125-139.

Huckabee, W. E. (1958). Relationships of Pyruvate and Lactate during anaerobic metabolism. 1. Effects of infusion of pyruvate or glucose and of hyperventilation. The Journal of Clinical Investigation, 37(2), 244-254.

Huggins, A. K., Skutsch, G., \& Baldwin, E. (1969). Ornithine-urea cycle enzymes in teleostean fish. Comparative Biochemistry and Physiology, 28(2), 587-602.

Hunn, J. B. (1985). Role of Calcium in Gill function in Freshwater Fishes. Comparative 
Biochemistry and Physiology, 82(3), 543-547.

Hung, C. C., Nawata, C. M., Wood, C. M., \& Wright, P. A. (2008). Rhesus glycoprotein and urea transporter genes are expressed in early stages of development of rainbow trout (Oncorhynchus mykiss). Journal of Experimental Zoology Part A: Ecological Genetics and Physiology, 309(5), 262-268.

Huntingford, F. A. (2004). Implications of domestication and rearing conditions for the behaviour of cultivated fishes. Journal of Fish Biology, 65 (1), 122-142.

Ip, Y. K., \& Chew, S. F. (2010). Ammonia production, excretion, toxicity, and defense in fish: a review. Frontiers in Physiology, 1, 1-20.

Ip, Y. K., Chew, S. F., \& Randall, D. J. (2001). Ammonia toxicity, tolerance and excretion. Fish Physiology, 19, 109-148.

Iwama, G. K., McGeer, J. C., Wright, P. A., Wilkie, M. P., \& Wood, C. M. (1997). Divalent cations enhance ammonia excretion in Lahontan cutthroat trout in highly alkaline water. Journal of Fish Biology, 50, 1061-1073.

Jentoft, S., Aastveit, A. H., Torjesen, P. A., \& Andersen, Ø. (2005). Effects of stress on growth, cortisol and glucose levels in non-domesticated Eurasian perch $(<\mathrm{i}>$ Perca fluviatilis $</ i>$ ) and domesticated rainbow trout $(<\mathrm{i}>$ Oncorhynchus mykiss</i>). Comparative Biochemistry and Physiology Part A: Molecular \& Integrative Physiology, 141(3), 353-358.

Johnsson, J. I., \& Abrahams, M. V. (1991). Interbreeding with Domestic Strain Increases Foraging under Threat of Predation in Juvenile Steelhead Trout (Oncorhynchus mykiss): An Experimental Study. Canadian Journal of Fisheries and Aquatic Sciences, 48(2), 243-247. 
Jones, A. W., \& Mackiewicz, J. S. (1969). Naturally Occurring Triploidy and Parthenogenesis in Atractolytocestus huronensis Anthony (Cestoidea: Caryophyllidea) from Cyprinus carpio L. in North America. The Journal of Parasitology, 55(6), 1105-1118.

Jones, B. E., Grant, W. D., Duckworth, A. W., \& Owenson, G. G. (1998). Microbial diversity of soda lakes. Extremophiles, 2, 191-200.

Jordan, H. M., \& Lloyd, R. (1964). The Resistance of Rainbow Trout (Salmo Gairdnerii Richardson) and Road (Rutilus Rutilus (L.)) to Alkaline Solutions. International Journal of Air and Water Pollution, 8, 405-409.

Juel, C. (1997). Lactate-proton cotransport in skeletal muscle. Physiological Review, 77(2), 321-358.

Keeley, E. R., Parkinson, E. A., \& Taylor, E. B. (2005). Ecotypic differentiation of native rainbow trout (Oncorhynchus mykiss) populations from British Columbia. Canadian Journal of Fish Aquatic Science, 62, 1523-1539.

Keeley, E. R., Parkinson, E. A., \& Taylor, E. B. (2007). The origins of ecotypic variation of rainbow trout: a test of environmental vs. genetically based differences in morphology. Journal of Evolutionary Biology, 20(2), 725-736.

Komen, H., \& Thorgaard, G. H. (2007). Androgenesis, gynogenesis and the production of clones in fishes: A review. Aquaculture, 269(1-4), 150-173.

Korwin-Kossakowski, M. (1992). Growth and survival of carp (Cyprinus carpio L.) larvae in alkaline water. Journal of Fish Biology, 40(6), 981-982.

Krueger, C. C., \& Waters, T. F. (1983). Annual Production of Macroinvertebrates in three streams of different water quality. Ecology, 64(4), 840-850. 
Kuzminski, H., \& Dobosz, S. (2010). Effect of sex reversal in rainbow trout (Oncorhynchus mykiss Walbaum) using 174 -methyltestosterone and 116hydroxyandrostenedione. Archives of Polish Fisheries, 18, 45-49.

Lamborot, M., \& Vasquez, M. (1998). A Triploid Lizard (Liolaemus gravenhorsti) from Chile. Journal of Herpetology, 32(4), 617-620.

Laurent, P., Dunel-Erb, S., Chevalier, C., \& Lignon, J. (1994). Gill epithelial cells kinetics in a freshwater teleost, Oncorhynchus mykiss during adaptation to ion-poor water and hormonal treatments. Fish physiology and biochemistry, 13(5), 353-370.

Laurent, P., \& Perry, S. F. (1990). Effects of cortisol on gill chloride cell morphology and ionic uptake in the freshwater trout, Salmo gairdneri. Cell and Tissue Research, 259(3), 429-442.

Laurent, P., Wilkie, M. P., Chevalier, C., \& Wood, C. M. (2000). The effect of highly alkaline water ( $\mathrm{pH}$ 9.5) on the morphology and morphometry of chloride cells and pavement cells in the gills of the freshwater rainbow trout: relationship to ionic transport and ammonia excretion. Canadian Journal of Zoology, 78, 307-319.

Leach, G. J., \& Taylor, M. H. (1982). The Effects of Cortisol Treatment on Carbohydrate and Protein Metabolism in Fundulus heteroclitus. General and Comparative Endocrinology, 48, 76-83.

Lepage, O., Øverli, Ø., Petersson, E., Järvi, T., \& Winberg, S. (2001). Differential stress coping in wild and domesticated sea trout. Brain, behavior and evolution, 56(5), 259-268. 
Leray, C., Colin, D. A., \& Florentz, A. (1981). Time Course of Osmotic Adaptation and Gill Energetics of Rainbow Trout (Salmo gairdneri R.) Following Abrupt Changes in External Salinity. Journal of Comparative Physiology, 144, 175181.

Lin, H., \& Randall, D. J. (1995). 9 Proton Pumps in Fish Gills. Fish Physiology, 14, 229255.

Lincoln, D. (1989). Triploid induction in rainbow trout using hydrostatic pressure. Trout News, 8, 8-10.

Lincoln, R. F., \& Scott, A. P. (1983). Production of all-female triploid rainbow trout. Aquaculture, 30(1-4), 375-380.

Lou, Y. D., \& Purdom, C. E. (1984). Polyploidy induced by hydrostatic pressure in rainbow trout, Salmo gairdneri Richardson. Journal of Fish Biology, 25(3), $345-351$.

Lund, P. (1970). A Radiochemical Assay for Glutamine Synthetase, and Activity of the Enzyme in Rat Tissue. Biochemical Journal, 118, 35-39.

MacCrimmon, H. R. (1971). World Distribution of rainbow trout (Salmo gairdneri). Journal of Fisheries Research Board of Canada, 28, 663-704.

MacCrimmon, H. R. (1972). World Distribution of Rainbow Trout (Salmo gairdneri): Further Observations. Journal of Fisheries Research Board of Canada, 29(12), $1788-1791$.

Mathias, K. L., Tsumura, K., \& Godin, T. I. (1996). Alkaline Lakes Enhancement. Habitat Conservation Fund Final Report British Columbia Ministry of Environment, Lands and Parks. 
McCormick, S. D., \& Naiman, R. J. (1984). Osmoregulation in the brook trout, Salvelinus fontinalis - II. Effects of size, age and photoperiod on seawater survival and ionic regulation. Comparative Biochemistry and Physiology Part A: Physiology, 79(1), 17-28.

McCusker, M. R., Parkinson, E., \& Taylor, E. B. (2000). Mitochondrial DNA variation in rainbow trout (Oncorhynchus mykiss) across its native range: testing biogeographical hypotheses and their relevance to conservation. Molecular Ecology, 9, 2089-2108.

McDonald, G., \& Milligan, L. (1997). Ionic, osmotic and acid-base regulation in stress. Fish stress and health in aquaculture, 62, 119-145.

McDonald, D. G., \& Robinson, J. G. (1993). Physiological responses of lake trout to stress: effects of water hardness and genotype. Transactions of the American Fisheries Society, 122(6), 1146-1155.

McDonald, D. G., \& Rogano, M. S. (1986). Ion Regulation by the Rainbow Trout, Salmo gairdneri, in Ion-Poor Water. Physiological Zoology, 59(3), 318-331.

McDonald, D. G., \& Wood, C. M. (1981). Branchial and renal acid and ion fluxes in the rainbow trout, Salmo gairdneri, at low environmental pH. Journal of Experimental Biology, 93, 101-118.

McGeer, J., \& Eddy, F. B. (1998). Ionic Regulation and Nitrogenous Excretion in Rainbow Trout Exposed to Buffered and Unbuffered Freshwater of pH 10.5. Physiological Zoology, 71(2), 179-190.

Milligan, C. L., \& Girard, S. S. (1993). Lactate metabolism in rainbow trout. Journal of Experimental Biology, 180, 175-193. 
Monfort, P., Kosenko, E., Erceg, S., Canales, J. J., \& Felipo, V. (2002). Molecular mechanism of acute ammonia toxicity: role of NMDA receptors. Neurochemistry International, 41, 95-102.

Mortimore, G. E., \& Poso, A. R. (1987). Intracellular Protein Catabolism and its control during nutrient deprivation and supply. Annual Review of Nutrition, 7, 539-564.

Murray, C. A., \& Ziebell, C. D. (1984). Acclimation of rainbow trout to high pH to prevent stocking mortality in summer. The Progressive Fish-Culturist, 46(3), 176-179.

Nawata, C. M., Hung, C. C. Y., Tsui, T. K. N., Wilson, J. M., Wright, P. A., \& Wood, C. M. (2007). Ammonia excretion in rainbow trout (Oncorhynchus mykiss): evidence for Rh glycoprotein and H+-ATPase involvement. Physiological Genomics, 31, 463-474.

Norenberg, M. D., Rama Rao, K. V., \& Jayakumar, A. R. (2004). Ammonia Neurotoxicity and the Mitochondrial Permeability Transition. Journal of Bioenergetics and Biomembranes, 36(4), 303-307.

Pawson, M. G. (2003). Triploid Trout in Native Trout Waters: Phase 1 (Technical Report No. W2-078/TR1).

Perry, S. F. (1997). THE CHLORIDE CELL: Structure and Function in the Gills of Freshwater Fishes. Annual Review of Physiology, 59, 325-347.

Perry, S. F., Goss, G. G., \& Laurent, P. (1992). The interrelationships between gill chloride cell morphology and ionic uptake in four freshwater teleosts. Canadian Journal of Zoology, 70, 1775-1786. 
Perry, S. F., \& Laurent, P. (1989). Adaptational responses of Rainbow trout to lowered external $\mathrm{NaCl}$ concentration: Contribution of the branchial chloride cell. The Journal of Experimental Biology, 147, 147-168.

Perry, S. F., \& Wood, C. M. (1985). Kinetics of Branchial Calcium uptake in the Rainbow Trout: effects of acclimation to various external calcium levels. Journal of Experimental Biology, 116, 411-433.

Pilley, C. M., \& Wright, P. A. (2000). The mechanisms of urea transport by early life stages of rainbow trout (Oncorhynchus mykiss). The Journal of Experimental Biology, 203, 3199-3207.

Pottinger, T. G., \& Carrick, T. R. (1999). Modification of the plasma cortisol response to stress in rainbow trout by selective breeding. General and comparative endocrinology, 116(1), 122-132.

Rahmatullah, M., \& Boyde, T. R. (1980). Improvements in the determination of urea using diacetyl monoxime; methods with and without deproteinisation. Clinica Chimica Acta, 107(1-2), 3-9.

Randall, D. J. (2011). Nitrogenous-Waste Balance. Excretion of Ammonia, 1437-1443.

Randall, D. J., \& Tsui, T. K. N. (2002). Ammonia toxicity in fish. Marine Pollution Bulletin, 45, 17-23.

Randall, D. J., \& Wright, P. A. (1989). The interaction between carbon dioxide and ammonia excretion and water pH in fish. Canadian Journal of Zoology, 67(12), 2936-2942.

Refstie, T. (1981). Tetraploid Rainbow trout produced by Cytochalasin B. Aquaculture, 25, 51-58. 
Ring, C., Patterson, S. M., Bacon, S. L., Veldhijzen van Zanten, J. J., Willemsen, G., \& Carroll, D. (2008). Reliability of hematocrit during rest and stress in healthy adults. Biological Psychology, 77(1), 63-68.

Robson, P. A. (2004). Fish Hatcheries. KnowBC.com. Retrieved January 16, 2014, from http://knowbc.com/ebc/Books/Encyclopedia-of-BC/F/Fish-Hatcheries

Sadler, J., Pankhurst, N. W., Pankhurst, P. M., \& King, H. (2000). Physiological stress responses to confinement in diploid and triploid Atlantic salmon. Journal of Fish Biology, 56(3), 506-518.

Sadler, J., Pankhurst, P. M., \& King, H. R. (2001). High prevalence of skeletal deformity and reduced gill surface area in triploid Atlantic salmon (Salmo salar L.). Aquaculture, 198(3-4), 369-385.

Sadler, J., Wells, R. M. G., Pankhurst, P. M., \& Pankhurst, N. W. (2000). Blood oxygen transport, rheology and haematological responses to confinement stress in diploid and triploid Atlantic salmon, Salmo salar. Aquaculture, 184, 349-361.

Sandbichler, A. M., Egg, M., Schwerte, T., \& Pelster, B. (2011). Claudin 28b and Factin are involved in rainbow trout gill pavement cell tight junction remodeling under osmotic stress. The Journal of Experimental Biology, 214, 1473-1487.

Sanderson, L. A., Wright, P. A., Robinson, J. W., Ballantyne, J. S., \& Bernier, N. J. (2010). Inhibition of glutamine synthetase during ammonia exposure in rainbow trout indicates a high reserve capacity to prevent brain ammonia toxicity. The Journal of Experimental Biology, 213, 2343-2353.

Schneeberger, E. E., \& Lynch, R. D. (2004). The tight junction: a multifunctional 
complex. American Journal of Physiology-Cell Physiology, 286, 1213-1228.

Scott, M. A. (2012). Performance of wild and domestic strains of diploid and triploid rainbow trout (Oncorhynchus mykiss) in response to environmental challenges.

Seidelin, M., Madsen, S. S., Byrialsen, A., \& Kristiansen, K. (1999). Effects of Insulinlike Growth Factor-I and Cortisol on $\mathrm{Na}^{+}, \mathrm{K}^{+}-\mathrm{ATPase}$ Expression in Osmoregulatory Tissues of Brown Trout (Salmo trutta). General and comparative endocrinology, 113(3), 331-342.

Shrimpton, J. M., Bernier, N. J., \& Randall, D. J. (1994). Changes in cortisol dynamics in wild and hatchery-reared juvenile coho salmon (Oncorhynchus kisutch) during smoltification. Canadian Journal of Fisheries and Aquatic Sciences, 51(10), 2179-2187.

Shrimpton, J. M., \& Mccormick, S. D. (1999). Responsiveness of gill Na+/K+-ATPase to cortisol is related to gill corticosteroid receptor concentration in juvenile rainbow trout. Journal of experimental biology, 202(8), 987-995.

Sidhu, S. (2012). Physiological \& Cellular Mechanisms of Ammonia Tolerance in the Goldfish (Carassius auratus). Wilfrid Laurier University.

Simon, D. C., Scalet, C. G., \& Dillon, J. C. (1993). Field Performance of Triploid and Diploid Rainbow Trout in South Dakota Ponds. North American Journal of Fisheries Management, 13(1), 134-140.

Skinner, J. S., \& McLellan, T. H. (1980). The Transition from Aerobic to Anaerobic Metabolism. Research Quarterly for Exercise and Sport, 51(1), 234-248.

Small, S. A., \& Benfey, T. J. (1987). Cell size in triploid salmon. Journal of 
Experimental Zoology, 241(3), 339-342.

Smart, G. (1976). The effect of ammonia exposure on gill structure of the rainbow trout (Salmo gairdneri). Journal of Fish Biology, 8, 471-475.

Smart, G. R. (1978). Investigations of the toxic mechanisms of ammonia to fish-gas exchange in rainbow trout (Salmo gairdneri) exposed to acutely lethal concentrations. Journal of Fish Biology, 12, 93-104.

Stevens, E. D. (1968). The effect of exercise on the distribution of blood to various organs in rainbow trout. Comparative Biochemistry and Physiology, 25(2), $615-625$.

Sutcliffe, D. W., \& Carrick, T. R. (1973). Studies on mountain streams in the English Lake District. Freshwater Biology, 3, 437-462.

Tang, V. W., \& Goodenough, D. A. (2003). Paracellular Ion Channel at the Tight Junction. Biophysical Journal, 84, 1660-1673.

Thorgaard, G. H., \& Gall, G. A. (1979). Adult triploids in a rainbow trout family. Genetics, 93, 961-973.

Thorgaard, G. H., Rabinovitch, P. S., Wentang Shen, M., Gall, G., Propp, J., \& Utter, F. (1982). Triploid Rainbow trout identified by flow cytometry. Aquaculture, 29, 305-309.

Thorgaard, G. H., Spruell, P., Wheeler, P. A., Scheerer, P. D., Peek, A. S., Valentine, J. J., \& Hilton, B. (1995). Incidence of albinos as a monitor for induced triploidy in rainbow trout. Aquaculture, 137(1-4), 121-130. 
Turner, J. D., Wood, C. M., \& Clark, D. (1983). Lactate and proton dynamics in the rainbow trout (Salmo gairdneri). Journal of Experimental Biology, 104(1), 247-268.

Van Der Boon, J., Van Den Thillart, G. E., \& Addink, A. D. F. (1991). The Effects of Cortisol Administration on intermediary metabolism in teleost fish. Comparative Biochemistry and Physiology, 100(1), 47-53.

Vincent, R. E. (1960). Some Influences of Domestication upon Three Stocks of Brook Trout (Salvelinus fontinalis Mitchill). Transactions of the American Fisheries Society, 89(1), 35-52.

Wagner, E. J., Arndt, R. E., Routledge, M. D., Latremouille, D., \& Mellenthin, R. F. (2006). Comparison of Hatchery Performance, Agonistic Behavior, and Poststocking Survival between Diploid and Triploid Rainbow Trout of Three Different Utah Strains. North American Journal of Aquaculture, 68, 63-73.

Wagner, E. J., Bosakowski, T., \& Intelmann, S. (1997). Mortality and the Stress Response of Rainbow Trout after Stocking. Transactions of the American Fisheries Society, 126(6), 985-998.

Wang, Y. S., Gonzalez, R. J., Patrick, M. L., Grosell, M., Zhang, C., Feng, Q., ... Wood, C. M. (2003). Unusual physiology of scale-less carp, Gymnocypris przewalskii, in Lake Qinghai: a high altitude alkaline saline lake. Comparative Biochemistry and Physiology Part A: Molecular \& Integrative Physiology, 134(2), 409-421.

Weil, L. S., Barry, T. P., \& Malison, J. A. (2001). Fast growth in rainbow trout is correlated with a rapid decrease in post-stress cortisol concentrations. Aquaculture, 193(3), 373-380. 
Weihrauch, D., Wilkie, M. P., \& Walsh, P. J. (2009). Ammonia and urea transporters in gills of fish and aquatic crustaceans. The Journal of Experimental Biology, 212, 1716-1730.

Wells, R. M. G., Tetens, V., \& Devries, A. L. (1984). Recovery from stress following capture and anaesthesia of antarctice fish: haematology and blood chemistry. Journal of Fish Biology, 25, 567-576.

Wells, R. M. G., \& Weber, R. E. (1991). Is there an optimal haematocrit for rainbow trout, Oncorhynchus mykiss (Walbaum)? An interpretation of recent data based on blood viscosity measurements. Journal of Fish Biology, 38, 53-65.

Wilkie, M. P. (1997). Mechanisms of Ammonia Excretion Across Fish Gills. Comparative Biochemistry and Physiology, 118(1), 39-50.

Wilkie, M. P. (2002). Ammonia Excretion and Urea Handling by Fish Gills: Present Understanding and Future Research Challenges. Journal of Experimental Zoology, 293, 284-301.

Wilkie, M. P., Laurent, P., \& Wood, C. M. (1999). The Physiological Basis for Altered $\mathrm{Na}+$ and $\mathrm{Cl}$ - Movements across the Gills of Rainbow Trout (Oncorhynchus mykiss) in Alkaline (pH=9.5) Water. Physiological and Biochemical Zoology, 72(3), 360-368.

Wilkie, M. P., Simmons, H. E., \& Wood, C. M. (1996). Physiological Adaptations of Rainbow Trout to Chronically Elevated Water $\mathrm{pH}(\mathrm{pH}=9.5)$. The Journal of Experimental Zoology, 274, 1-14.

Wilkie, M. P., \& Wood, C. M. (1991). Nitrogenous Waste Excretion, Acid-Base Regulation, and Ionoregulation in Rainbow Trout (Oncorhynchus mykiss) 
Exposed to Extremely Alkaline Water. Physiological Zoology, 64(4), 10691086.

Wilkie, M. P., \& Wood, C. M. (1994). The effects of extremely alkaline water (pH 9.5) on rainbow trout gill function and morphology. Journal of Fish Biology, 45, 87-98.

Wilkie, M. P., \& Wood, C. M. (1995). Recovery from High pH Exposure in the Rainbow Trout: White Muscle Ammonia Storage, Ammonia Washout, and the Restoration of Blood Chemistry. Physiological Zoology, 68(3), 379-401.

Wilkie, M. P., Wright, P. A., Iwama, G. K., \& Wood, C. M. (1994). The of the Lahontan Physiological Aldaptations Cutthroat trout (Oncorhynchus clarki henshawl) following Transfer from Well Water to the Highly Alkaline Waters of Pyramid Lake, Nevada (pH9.4). Physiological Zoology, 67(2), 355-380.

Wilson, J. M., Iwata, K., Iwama, G. K., \& Randall, D. J. (1998). Inhibition of ammonia excretion and production in rainbow trout during severe alkaline exposure. Comparative Biochemistry and Physiology, 121, 99-109.

Wilson, R. W., Wright, P. A., Munger, S., \& Wood, C. M. (1994). Ammonia Excretion in freshwater rainbow trout (Oncorhynchus mykiss) and the importance of gill boundary layer acidification: Lack of evidence for $\mathrm{Na}+/ \mathrm{NH} 4+$ exchange. The Journal of Experimental Biology, 191, 37-58.

Wood, C. M., \& Nawata, C. M. (2011). A nose-to-nose comparison of the physiological and molecular responses of rainbow trout to high environmental ammonia in seawater versus freshwater. The Journal of Experimental Biology, 214, 35573569. 
Wood, C. M., Perry, S. F., Wright, P. A., Bergman, H. L., \& Randall, D. J. (1989). Ammonia and urea dynamics in the Lake Magadi tilapia, a ureotelic teleost fish adapted to an extremely alkaline environment. Respiration Physiology, $77,1-20$.

Wood, C. M., \& Randall, D. J. (1973). Sodium Balance in the Rainbow Trout (Salmo gairdneri) during extended exercise. Journal of Comparative Physiology, 82, $235-256$.

Woodward, C. C., \& Strange, R. J. (1987). Physiological Stress Responses in Wild and Hatchery-Reared Rainbow Trout. Transactions of the American Fisheries Society, 116(4), 574-579.

Wright, P. A. (1995). Nitrogen Excretion: Three end products, many physiological roles. The Journal of Experimental Biology, 198, 273-281.

Wright, P. A., Felskie, A., \& Anderson, P. M. (1995). Induction of ornithine-urea cycle enzymes and nitrogen metabolism and excretion in rainbow trout (Oncorhynchus mykiss) during early life stages. Journal of Experimental Biology, 198, 127-135.

Wright, P. A., Iwama, G. K., \& Wood, C. M. (1993). Ammonia and Urea excretion in Lahontan cutthroat trout (Oncorhynchus clarki henshawi) adapted to the highly pyramid lake (pH 9.4). Journal of Experimental Biology, 175, 153-172.

Wright, P. A., \& Wood, C. M. (1985). An analysis of branchial ammonia excretion in the freshwater rainbow trout: Effects of environmental $\mathrm{pH}$ change and sodium uptake blockade. Journal of Experimental Biology, 114, 329-353.

Wright, P. A., \& Wood, C. M. (2009). A new paradigm for ammonia excretion in 
aquatic animals: role of Rhesus (Rh) glycoproteins. Journal of Experimental Biology, 212, 2303-2312.

Wright, P. A., \& Wood, C. M. (2012). Seven things fish know about ammonia and we don't. Respiratory physiology \& neurobiology, 184(3), 231-240.

Xu, Y., \& Tao, Y. X. (2004). Involvement of the NMDA receptor/nitric oxide signal pathway in platelet-activating factor-induced neurotoxicity. Neuroreport, 15(2), 263-266.

Yesaki, T. Y., \& Iwama, G. K. (1992). Survival, Regulation, Regulation, and Ammonia Excretion in Rainbow Trout in Highly Alkaline Hard Water. Physiological Zoology, 65(4), 763-787.

Yesaki, T. Y., Scheer, K. W., \& Greiner, D. L. (1996). Production-scale pressure shocking of rainbow trout (Oncorhynchus mykiss) in British Columba. Proceedings of the 47th Annual Northwest Fish Culture Conference, 170, 173.

Yesaki, T. Y., Tsumura, K. (1992). Alkaline Lakes Enhancement: Habitat Conservation Fund Progress Report (1991-1992)

Zimmer, A. M., Brauner, C. J., \& Wood, C. M. (2014). Ammonia transport across the skin of adult rainbow trout (Oncorhynchus mykiss) exposed to high environmental ammonia (HEA). Journal of Comparative Physiology B, 184(1), 77-90. 